\title{
Complexation by organic matter controls uranium mobility in anoxic sediments
}

Sharon E. Bone ${ }^{1 *}$, John Cliff ${ }^{2}$, Karrie Weaver ${ }^{3}$, Christopher J. Takacs ${ }^{1}$, Scott Roycroft ${ }^{1}$, Scott Fendorf ${ }^{2}$, John R. Bargar ${ }^{1}$

${ }^{1}$ Stanford Synchrotron Radiation Lightsource, SLAC National Accelerator Laboratory, Menlo Park, CA 94025

${ }^{2}$ Environmental Molecular Sciences Laboratory, Pacific Northwest National Laboratory, Richland, WA 99354

${ }^{3}$ Earth System Science Department, Stanford University, Stanford, California 94305, USA

*Email: shbone@slac.stanford.edu

\author{
Supporting Information \\ 28 pages \\ 14 Tables \\ 18 Figures
}




\section{Total Acid Digestion of Density Fractions}

To ensure complete digestion of refractory minerals, silicates and other compounds that are not soluble in nitric acid, a bench top dissolution was performed on each density fraction. The work was performed in a class 1000 clean lab with class 100 workstations; all samples were processed in Savillex ${ }^{\circledR}$ capped vials and all reagents are Optima ${ }^{\circledR}$ grade high purity acids (less than $1 \mathrm{ppt} U$ ). Samples containing organic matter were subjected to repeated attacks of a mixture of concentrated peroxide $\left(\mathrm{H}_{2} \mathrm{O}_{2}\right)$ and concentrated nitric acid $\left(\mathrm{HNO}_{3}\right)$. Samples were allowed to react overnight and then slowly heated until the liquid evaporated and the sample was dry. After destruction of the organic matter, the organic fractions and the mineral-rich fractions were treated in the same manner. Three parts concentrated nitric acid and one part concentrated hydrofluoric acid were applied to the dried samples. Samples were allowed to react cold overnight and then were heated at 90 ${ }^{\circ} \mathrm{C}$ for at least 12 hours to promote digestion. Sample solutions were evaporated to dryness and taken up in aqua regia ( 3 parts concentrated $\mathrm{HCl}$ to 1 part concentrated nitric acid) to ensure that the sample was fully digested and no insoluble fluorides remained. Clear solutions were considered fully digested and evaporated to dryness. Cloudy solutions or solutions with undissolved sediment were dried down and again reacted with nitric and hydrofluoric acids. The samples were dried and then the remaining solid was dissolved in $2 \% \mathrm{HNO}_{3}$ for measurement via ICP-MS.

\section{Absence of $U$ from sediments with non-detectable $U$ concentrations via nanoSIMS and details of image analysis}

NanoSIMS images were collected on sediment in which U was non-detectable $(0.4$ $\mu \mathrm{g} / \mathrm{g}$; via X-ray fluorescence) to test whether the NanoSIMS measurements were susceptible to detecting artifactual $U$, for instance high molecular weight adducts with masses close to that of ${ }^{238} \mathrm{U}^{16} \mathrm{O}^{+}$. The sediment was collected from the riverbank, in proximity to the high-U riverbank sample examined in this study. No $U$ was detected via NanoSIMS. Figure S1 shows images of the ${ }^{56} \mathrm{Fe}^{+}$distribution, which shows where many of the particles were located, as well as the distribution of ${ }^{238} \mathrm{U}^{16} \mathrm{O}^{+}$.

Figure S1: NanoSIMS images of sediment without $U$. Images show the distribution of Fe and $U$.
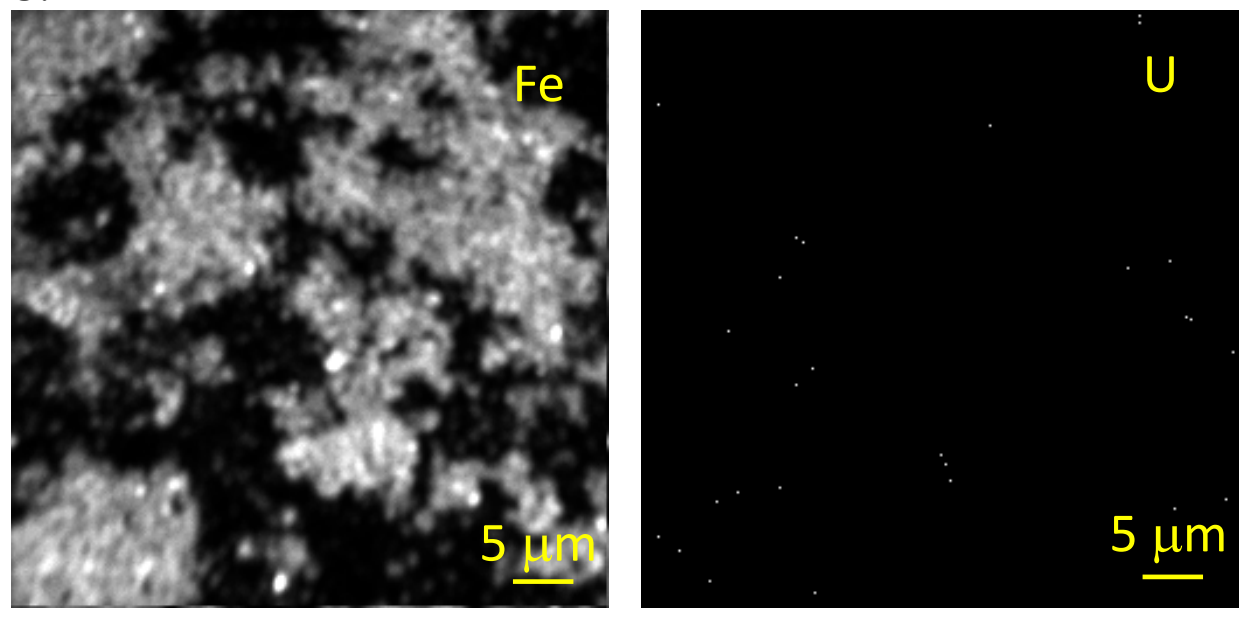
Alignment of negative and positive ion images was performed by identifying 15 30 common point-like features in positive/negative images followed by fitting to a second order polynomial transformation function that allows for rotation, shear, and scale changes along both the fast and slow scan directions. Higher order terms in transformation function were not deemed necessary. Image regridding/transformation using bilinear interpolation was then performed using the EMSF/ESMPy ${ }^{1}$ software frameworks.

When possible, regions imaged via STXM were also imaged using nanoSIMS so that the speciation of carbon could be assessed in locations where the $\mathrm{C}$ and $\mathrm{U}$ distributions overlapped. There was one particle imaged (Figure $2 \mathrm{~b}$ and $2 \mathrm{~h}$, main text) in which $\mathrm{C}$ was detected via STXM but not via nanoSIMS, likely due to charging of the sample surface, which can prevent secondary ion detection. Although a problem in this one instance, STXM and nanoSIMS C distributions generally agreed well.

Scatter plots showing the $U$ intensity versus the intensity of other elements were generated in $\mathrm{SMAK}^{2}$. Before comparison, images were modified using a Gaussian blur function at $80 \%$ standard deviation in SMAK to reduce noise. The positive and negative ion images all were collected with the same pixel dimensions, which is required for correlation analysis. However, the positive and negative ion images have inherently different spatial resolutions due to the different sizes of the $\mathrm{Cs}^{+}$and $\mathrm{O}^{-}$ion beams. This difference in resolution serves to decrease the correlation between any of the negative ions and ${ }^{238} \mathrm{U}^{16} \mathrm{O}^{+}$.

The majority of the particles imaged did not contain any $U$, since $U$ was a minor constituent of the sample relative to the other elements imaged. This fact weakened all correlations between $U$ and the other elements. In addition to doing correlation analysis on the entire image, we therefore sought to determine the intensities of elements for only Ucontaining particles using the particle statistics package available in SMAK ${ }^{2}$. This analysis allowed us to assess the frequency with which those particles that were enriched in U were also enriched in another element. The U-containing particles were selected from the images using an inverse binary thresholding method in which all pixels were assigned to belong to a particle if they exhibited $U$ intensities $>2$ to $>10 \%$ of the highest $U$ intensity observed in the entire image. All pixels with $U$ intensities below this threshold were considered to be part of the background. It was necessary to adjust the threshold between 2 and $10 \%$ because images that contained pixels with very high $U$ counts exhibited very large ranges of $U$ intensities, whereas images with low $U$ counts tended to exhibit smaller ranges in $U$ intensities. In order to avoid counting noise as pixels, particles were not considered unless they were composed of a minimum number of pixels, which was chosen to be six. The software designates each particle as a "region of interest" (ROI). 


\section{Bulk sediment composition}

Table S1: Elemental composition of sediments. One standard deviation, based on three replicate measurements, is given in parentheses.

\begin{tabular}{cccccccc} 
Sample & wt. & wt. & [U] & Fe (wt. \%) & S (wt. \%) & P (wt. \%) & Ca (wt. \%) \\
\hline Oxbow & 0.1 & 1.7 & $139(5)$ & $1.7(2)$ & $0.50(3)$ & $0.04(1)$ & $3.2(2)$ \\
Riverbank & 0.01 & 0.5 & $102(10)$ & $0.9(1)$ & $0.30(1)$ & $0.03(2)$ & $1.6(1)$ \\
\hline
\end{tabular}

\section{Bulk X-ray Absorption Spectroscopy}

Figure S2: S K-edge X-ray absorption spectra and linear combination fits. The XAS for the riverbank sediment is shown in (a); the oxbow lake sediment in (b). The experimental spectra are provided in black; fits in red. Samples were fit as a linear combination of FeS (mackinawite; blue), pyrite (purple), $\mathrm{S}_{8}$ (zerovalent sulfur; pink), cysteine (yellow), and sulfate (green).

(a)

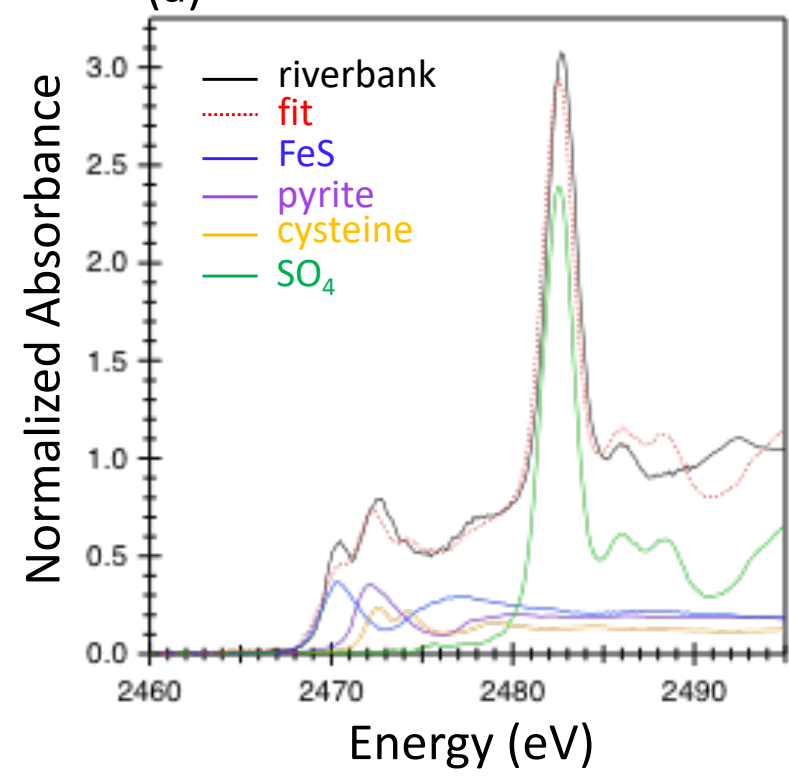

(b)

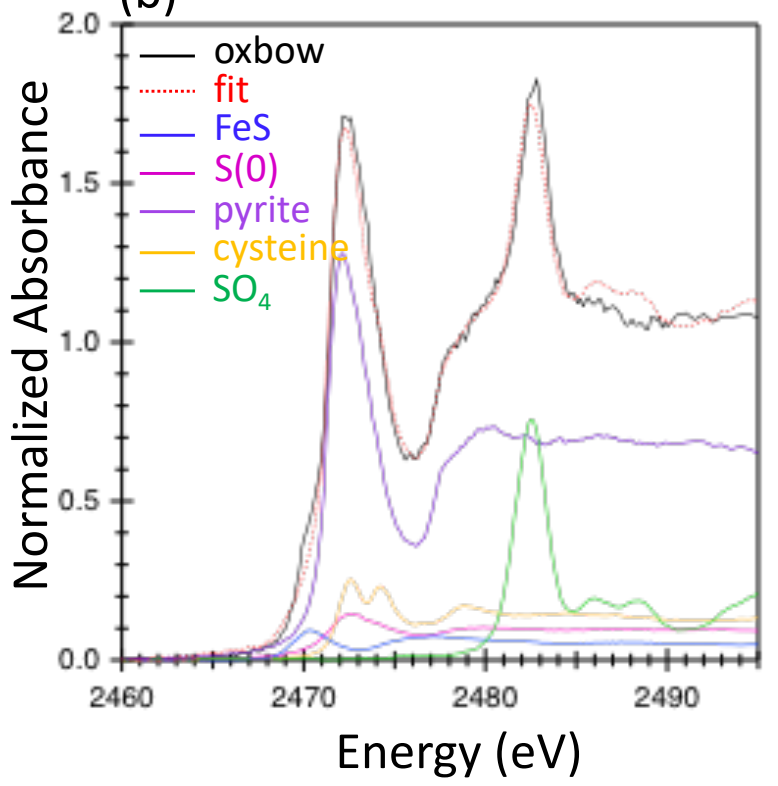

Table S2: Fraction S oxidation state as determined via linear combination fitting.

\begin{tabular}{|c|c|c|}
\hline Reference & Riverbank sediment & Oxbow lake sediment \\
\hline $\mathrm{FeS}$ (mackinawite) & 0.17 & 0.04 \\
\hline $\mathrm{FeS}_{2}$ (pyrite) & 0.17 & 0.63 \\
\hline $\mathrm{S}_{8}$ (zerovalent sulfur) & & 0.09 \\
\hline $\mathrm{HO}_{2} \mathrm{CCHCH}_{2} \mathrm{SH}$ & 0.12 & 0.13 \\
(cysteine) & & 0.11 \\
\hline $\mathrm{K}_{2} \mathrm{SO}_{4}{ }^{2-}$ (sulfate) & 0.33 & \\
\hline
\end{tabular}


Figure S3: U L III-edge XANES spectra and linear combination fits. The XANES spectra for the whole oxbow lake and riverbank sediment, as well as the light, middle and heavy fractions of the oxbow lake sediment are shown (black lines) along with linear combination fits (grey dotted lines). Samples were fit as a linear combination of molecular U(IV) and U(VI)-adsorbed ferrihydrite.
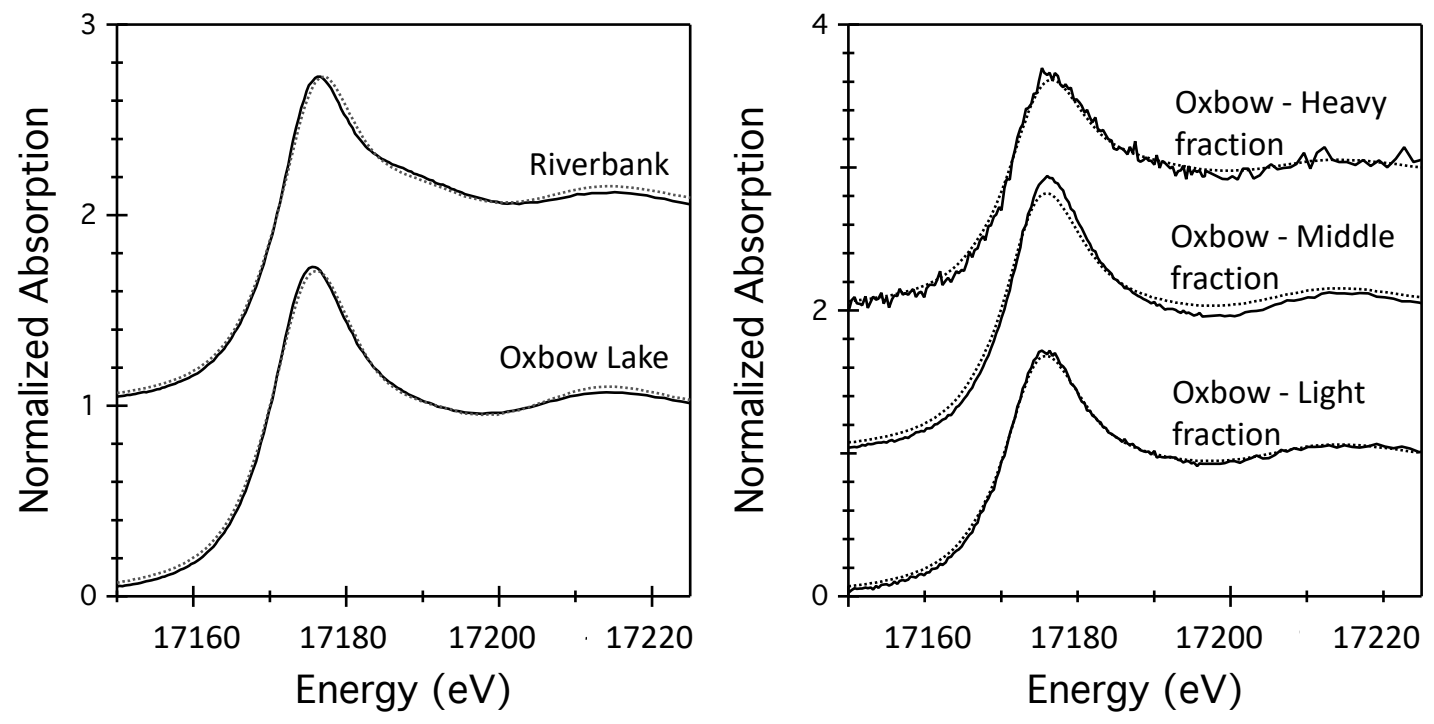

Table S3: Fitted fractions of U(IV) and U(VI) from linear combination fits. The error on the linear combination fits are assumed to be $c a .10 \%$. Samples were fit as a linear combination of molecular U(IV) and U(VI)-adsorbed ferrihydrite.

\begin{tabular}{|c|c|c|}
\hline Sample & Fraction U(IV) & Fraction U(VI) \\
\hline Oxbow Lake & 0.93 & 0.09 \\
\hline Riverbank & 0.55 & 0.54 \\
\hline Oxbow-Light fraction & 0.91 & 0.07 \\
\hline Oxbow-Middle fraction & 0.96 & 0.11 \\
\hline Oxbow-Heavy fraction & 0.64 & 0.35 \\
\hline
\end{tabular}


Figure S4: U LIII-edge Fourier transformed EXAFS spectra and fits. The EXAFS spectra for the oxbow lake and riverbank sediment are shown (black lines) along with fits (red dotted lines).
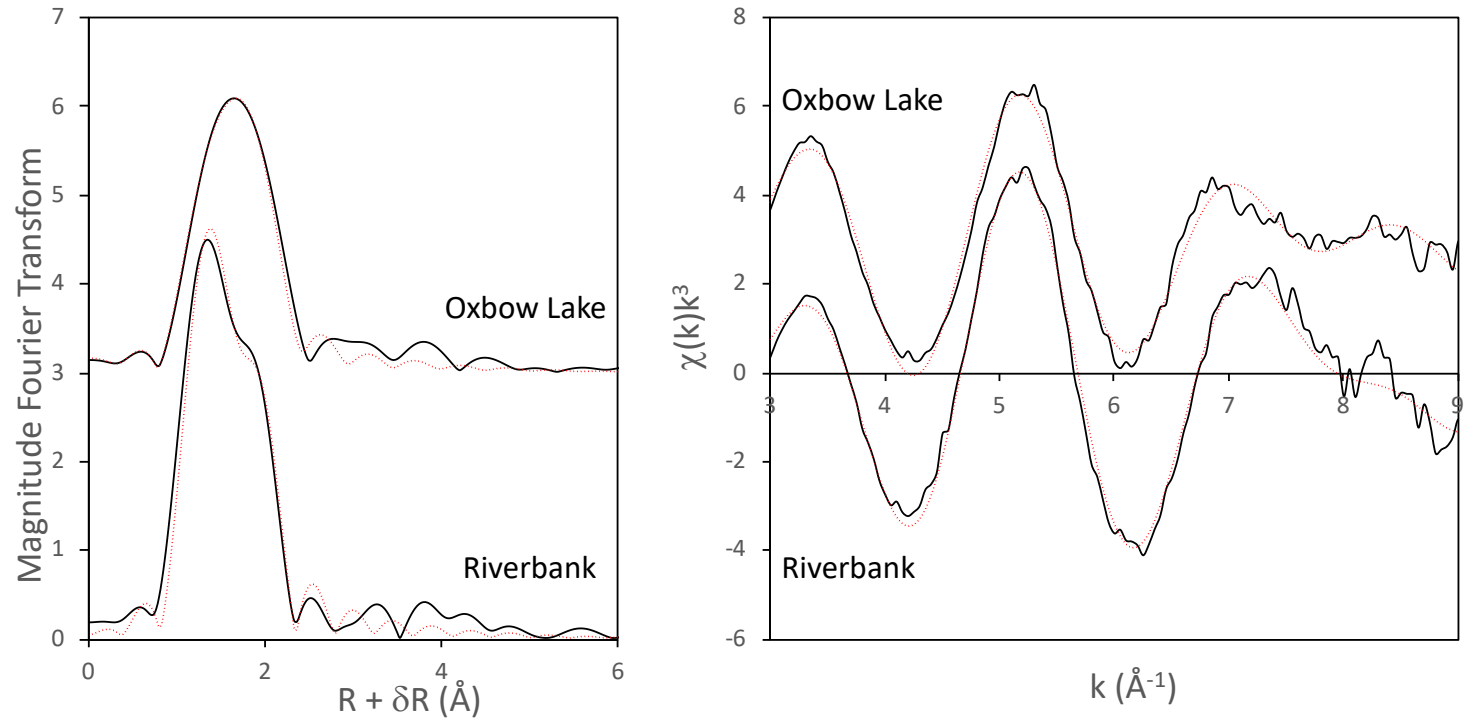

Table S4: Fitting parameters for riverbank and oxbow lake sediments. Samples were fit between $\mathrm{R}=1$ and $3 \AA$ (Fourier transformed between $\mathrm{k}=3$ and $9 \AA^{-1}$ ). The number of independent points was 7 . Values in parentheses indicate the error on the fitted values as one standard deviation. The amplitude reduction factor $\left(\mathrm{S}_{0}^{2}\right)$ was assumed to be $1^{3}$.

\begin{tabular}{cccccc}
\multicolumn{7}{c}{$\mathbf{U}-\mathbf{O}_{\text {equitorial }}$} \\
\hline Sample & $\mathbf{N}$ & $\mathbf{R}(\mathbf{\AA})$ & $\boldsymbol{\sigma}^{\mathbf{2}}\left(\mathbf{\AA}^{\mathbf{2}}\right)$ & $\Delta \mathbf{E}(\mathbf{e V})$ & $\mathbf{R}$-factor \\
\hline oxbow & $7.0(2)$ & $2.35(2)$ & $0.014(4)$ & $(0.07)(2.5)$ & 0.017 \\
riverbank & $5.7(8)$ & $2.35(2)$ & $0.010(2)$ & $1.58(1.8)$ & 0.0035 \\
\hline \multicolumn{5}{c}{$\mathbf{U}-\mathbf{O}_{\text {axial }}$} \\
\hline Sample & $\mathbf{N}$ & $\mathbf{R}(\mathbf{\AA})$ & $\boldsymbol{\sigma}^{\mathbf{2}}\left(\mathbf{\AA}^{\mathbf{2}}\right)$ \\
\hline oxbow & $0.6(2)$ & $1.76(2)$ & $0.003^{1}$ \\
riverbank & $1.6(1)$ & $1.78(1)$ & $0.003^{1}$ \\
\hline${ }^{1}$ Set based on value reported for $\mathrm{U}=$ O bond in Bone et al. ${ }^{3}$
\end{tabular}

${ }^{1}$ Set based on value reported for $\mathrm{U}=\mathrm{O}$ bond in Bone et al. ${ }^{3}$ 


\section{Mass Recovery from Density Fractions}

Table S5: Mass recover from density fractions.

\begin{tabular}{|c|c|c|c|c|}
\hline & \multicolumn{4}{|c|}{ mass recovery } \\
\hline Sample & \% light & \% medium & \% heavy & SUM \\
\hline Oxbow lake a & 1.9 & 27.7 & 54.7 & 84.3 \\
\hline Oxbow lake b & 3.2 & & 84.7 & \\
\hline Oxbow lake c & 3.2 & 48.2 & 57.1 & 108.5 \\
\hline Oxbow lake d & 2.7 & 29.3 & 46.7 & 78.8 \\
\hline average & $\mathbf{2 . 8}$ & $\mathbf{3 5 . 1}$ & $\mathbf{6 0 . 8}$ & $\mathbf{9 0 . 5}$ \\
\hline $\begin{array}{c}\text { Standard } \\
\text { deviation }\end{array}$ & $\mathbf{0 . 6}$ & $\mathbf{1 1 . 4}$ & $\mathbf{1 6 . 5}$ & $\mathbf{1 5 . 8}$ \\
\hline Riverbank a & 1.4 & 16.1 & 57.5 & 74.9 \\
\hline Riverbank b & 1.4 & & 75.3 & \\
\hline Riverbank c & 2.3 & 12.7 & 76.9 & 91.9 \\
\hline average & $\mathbf{1 . 7}$ & $\mathbf{1 4 . 4}$ & $\mathbf{6 9 . 9}$ & $\mathbf{8 3 . 4}$ \\
\hline $\begin{array}{c}\text { Standard } \\
\text { deviation }\end{array}$ & $\mathbf{0 . 5}$ & $\mathbf{2 . 4}$ & $\mathbf{1 0 . 8}$ & $\mathbf{1 2}$ \\
\hline
\end{tabular}

\section{Comparison of acid digested and XRF U concentrations}

Table S6: Concentrations of $\mathrm{U}$ determined via acid digestion $\left(\mathrm{HNO}_{3}\right.$ or $\left.\mathrm{HF}\right)$ and XRF. Dashed line indicates not measured.

\begin{tabular}{|c|c|c|c|}
\hline Sample & $\begin{array}{c}{[\mathbf{U}] \text { (ppm) }} \\
\text { - HNO3 }\end{array}$ & $\begin{array}{c}\text { [U] (ppm) } \\
-\mathbf{H F}\end{array}$ & $\begin{array}{c}\text { [U] (ppm) } \\
-\mathbf{X R F}\end{array}$ \\
\hline oxbow, light & 173.5 & 143.0 & - \\
\hline oxbow, medium & $27.3(3.6)$ & 77.1 & - \\
\hline oxbow, heavy & $24.4(0.2)$ & 12.8 & $6.4(1.7)$ \\
\hline oxbow, whole & - & $107.3(8.6)$ & $139(5)$ \\
\hline $\begin{array}{c}\text { riverbank, light } \\
\text { riverbank, } \\
\text { medium, }\end{array}$ & 774.3 & - & - \\
\hline riverbank, heavy & $10.7(84.1)$ & 313.9 & - \\
\hline Riverbank, whole & - & 108.0 & $2.2(0.9)$ \\
\hline
\end{tabular}

The fraction of $U$ recovered from the density fractions was estimated by multiplying the concentration of $\mathrm{U}$ measured via HF in each fraction ( $\mathrm{mg} \mathrm{U}$ per $\mathrm{kg}$ light, middle or heavy sediment presented in Table S6) by the total mass recovered in each fraction (i.e. the values presented in Table S5). These new U concentrations (mg U per kg sediment) were summed 
and divided by the total concentration of U measured via HF (presented in Table S6) in the whole sediment. The recovered percent of $U$ in the oxbow lake was $36 \%$; in the riverbank, it was $58 \%$.

\section{NanoSIMS images}

Figure S5: NanoSIMS images of the oxbow lake sediment, light fraction. Arrow indicates particle where $\mathrm{U}$ and $\mathrm{C}$ overlap.
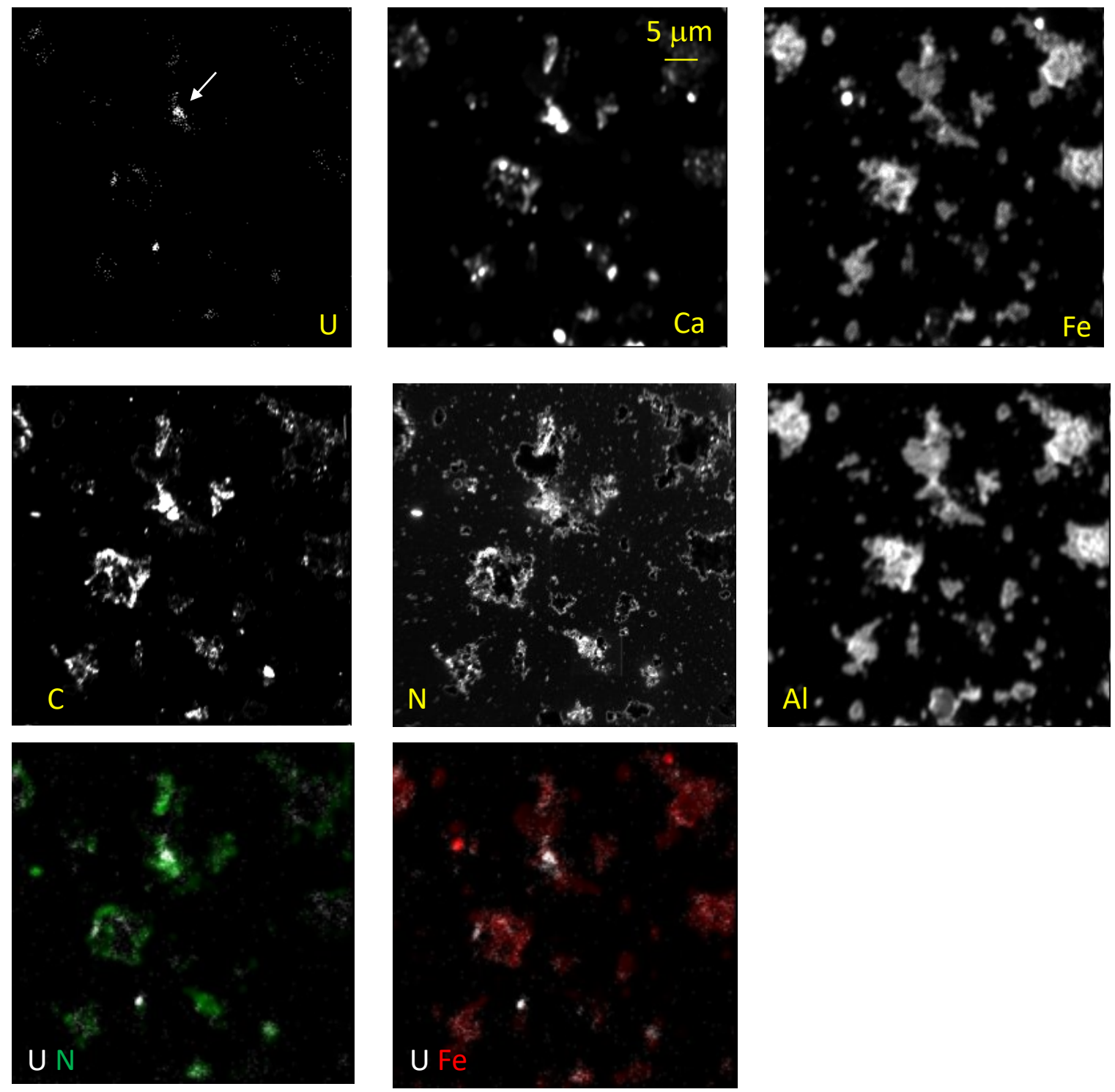
Figure S6: Box plots showing elemental distributions within ROIs for oxbow, light fraction. Box plots showing the median (orange line), upper and lower quartiles (green box), range (green line), and outlying points (green crosses) for the intensities of U, C, N, $\mathrm{Ca}, \mathrm{Al}$ and $\mathrm{Fe}$ within all U-containing particles present in the region shown in Figure S5. Each particle is referenced by its ROI number (x-axis). The arrows draw attention to the particles that exhibit the highest $U$ intensities, as well as the other elements that exhibit elevated intensities for those same particles.
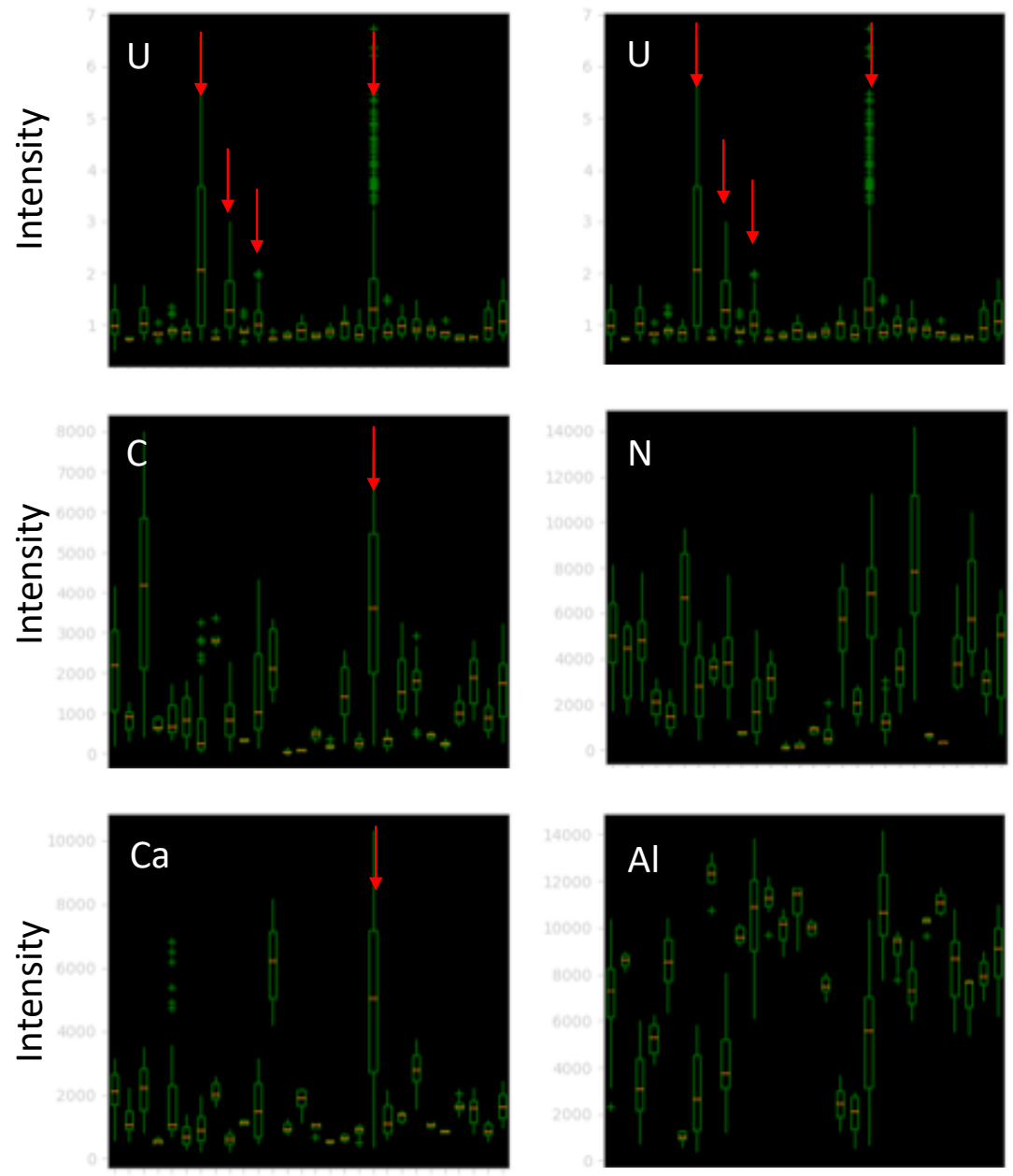

ROI \#

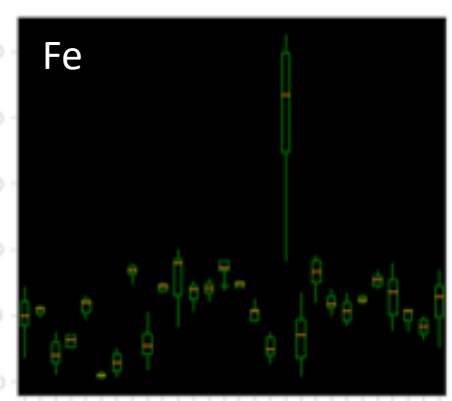

ROI \# 
Figure S7: NanoSIMS images of the oxbow lake sediment, middle fraction.
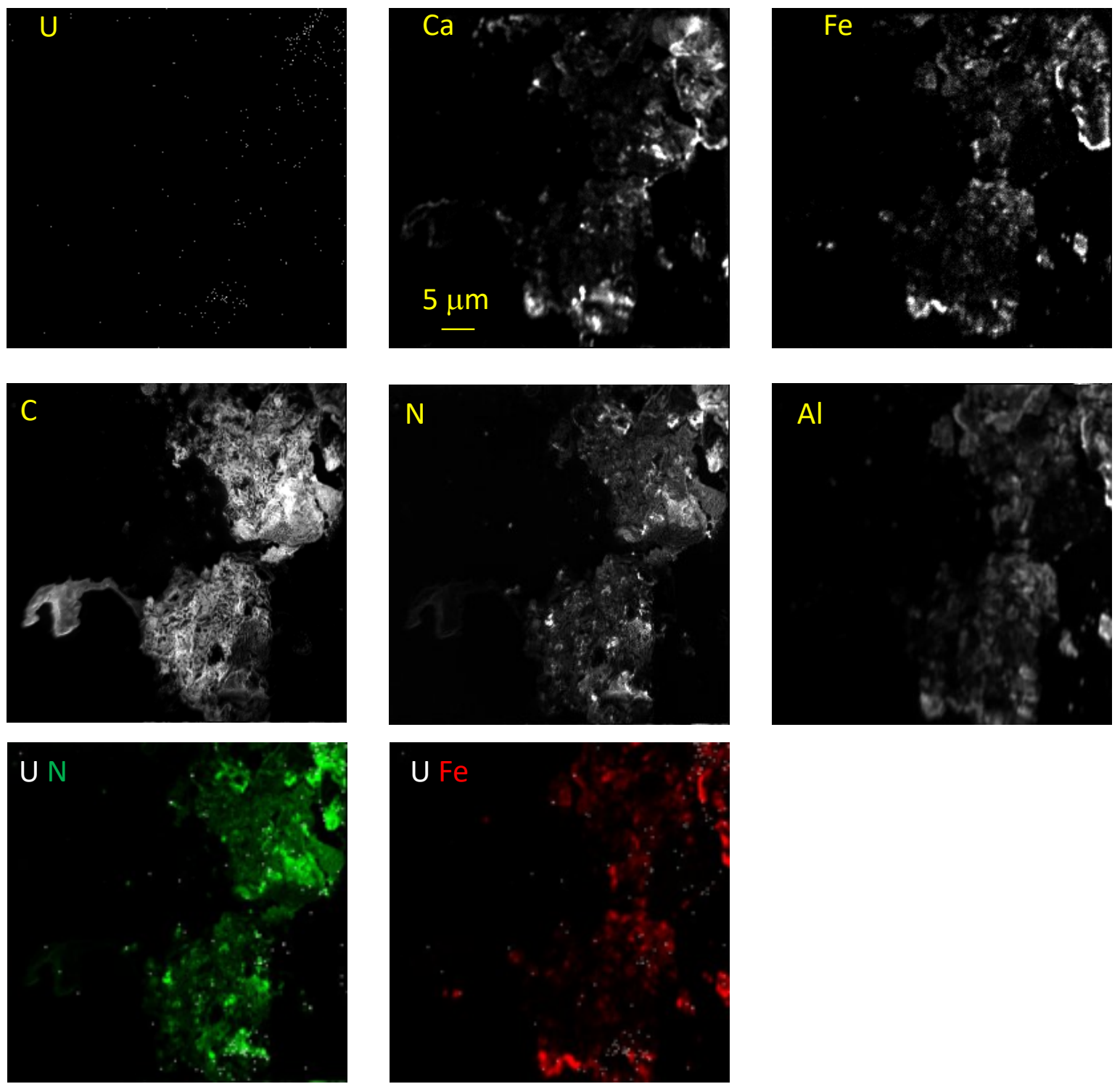
Figure S8: Box plots showing elemental distributions within ROIs for oxbow, middle fraction. Box plots showing the median (orange line), upper and lower quartiles (green box), range (green line), and outlying points (green crosses) for the intensities of U, C, N, $\mathrm{Ca}, \mathrm{Al}$ and $\mathrm{Fe}$ within all U-containing particles present in the region shown in Figure S7. Each particle is referenced by its ROI number (x-axis).
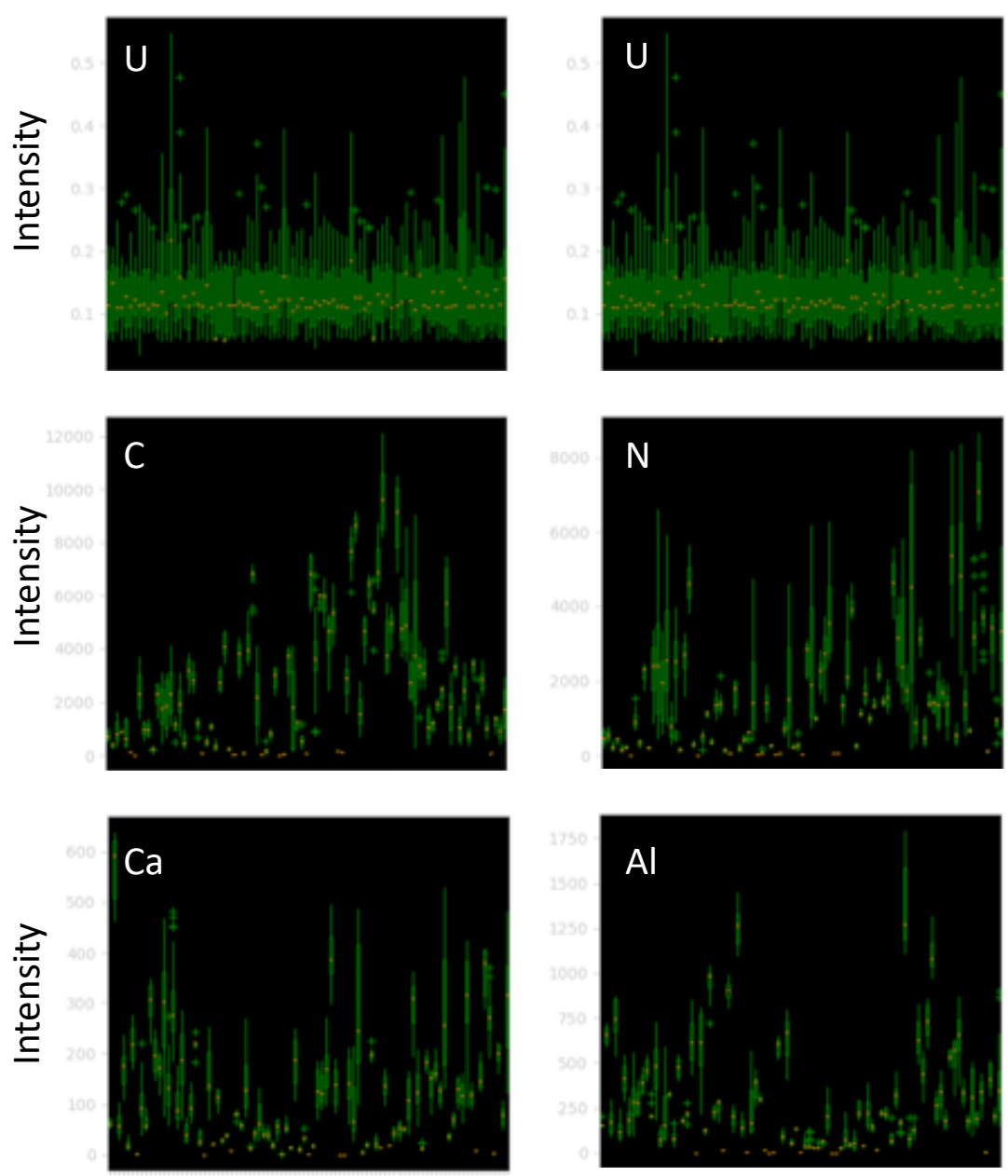

ROI \#

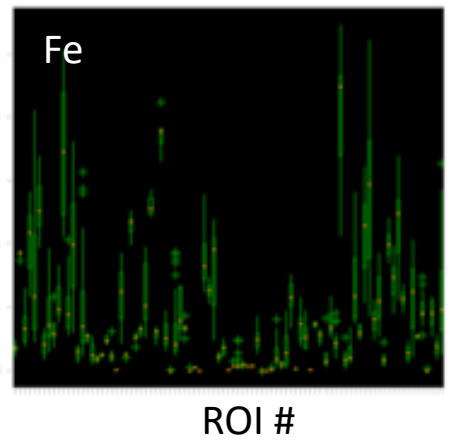


Figure S9: NanoSIMS images of the oxbow lake sediment, heavy fraction. Arrows indicate particles where $\mathrm{U}$ and $\mathrm{C}$ or $\mathrm{U}$ and $\mathrm{Ca}$ overlap.
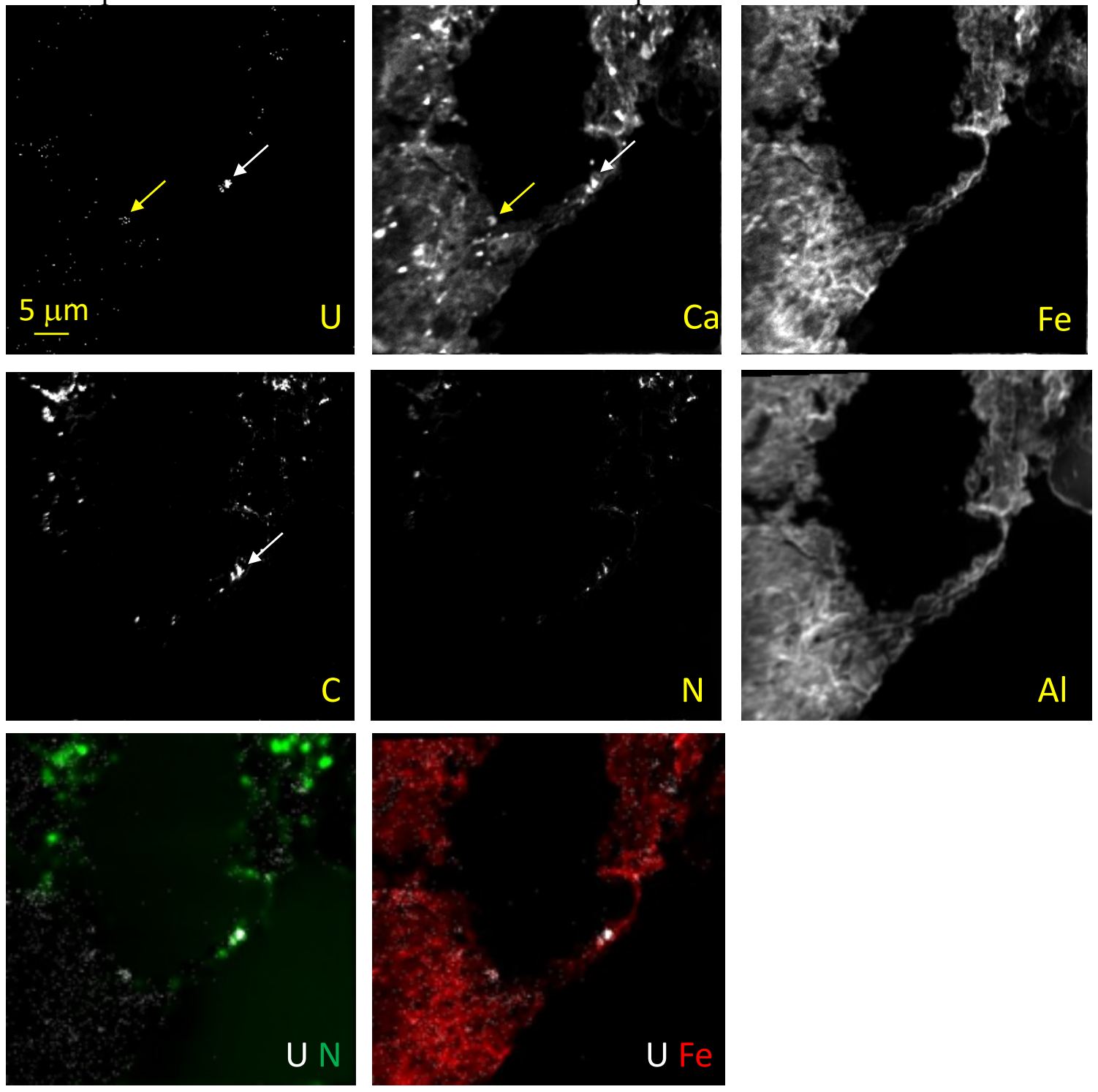
Figure S10: Box plots showing elemental distributions within ROIs for oxbow, heavy fraction. Box plots showing the median (orange line), upper and lower quartiles (green box), range (green line), and outlying points (green crosses) for the intensities of U, C, N, $\mathrm{Ca}, \mathrm{Al}$ and $\mathrm{Fe}$ within all U-containing particles present in the region shown in Figure S9. Each particle is referenced by its ROI number (x-axis). The arrows draw attention to the particles that exhibit the highest $U$ intensities, as well as the other elements that exhibit elevated intensities for those same particles.
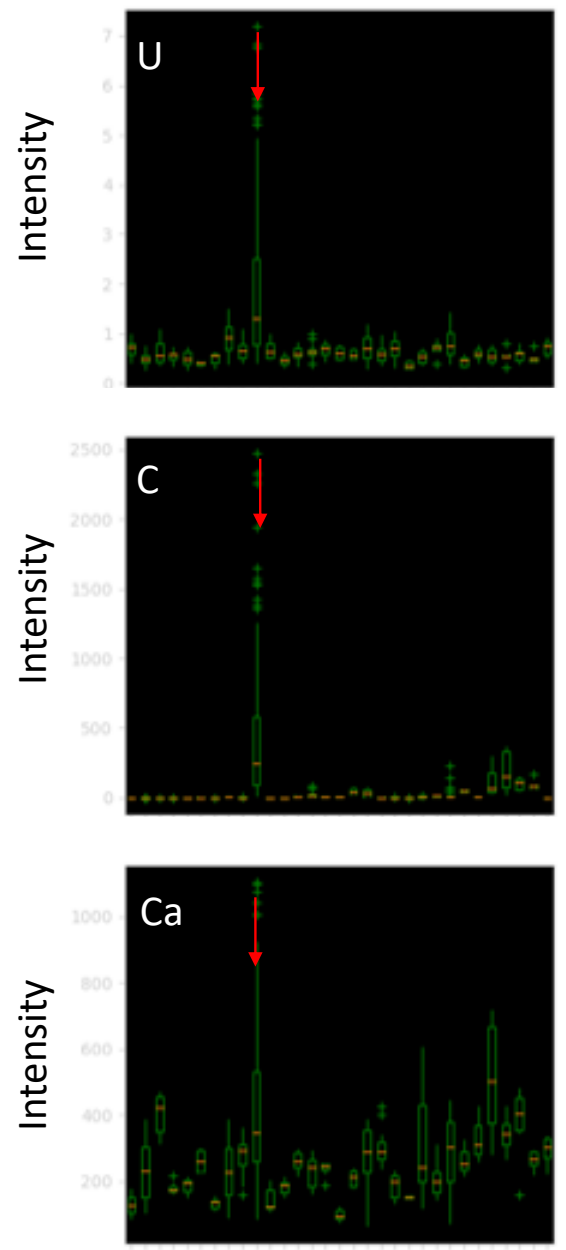

ROI \#
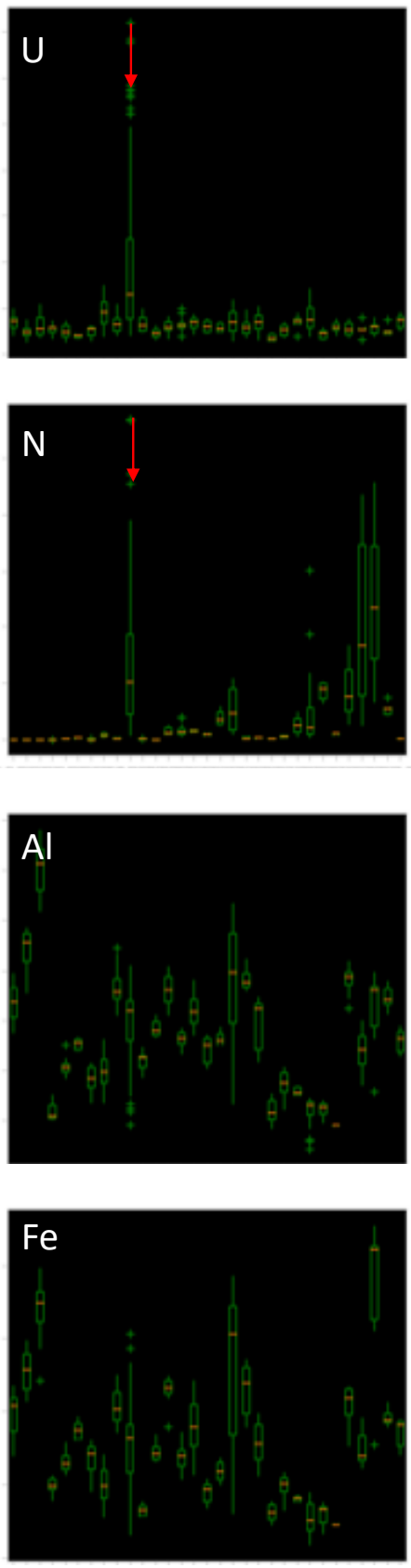

ROI \# 
Figure S11: NanoSIMS images of the riverbank sediment, light fraction. Arrows indicate particles where $\mathrm{U}, \mathrm{C}$, and Ca overlap.
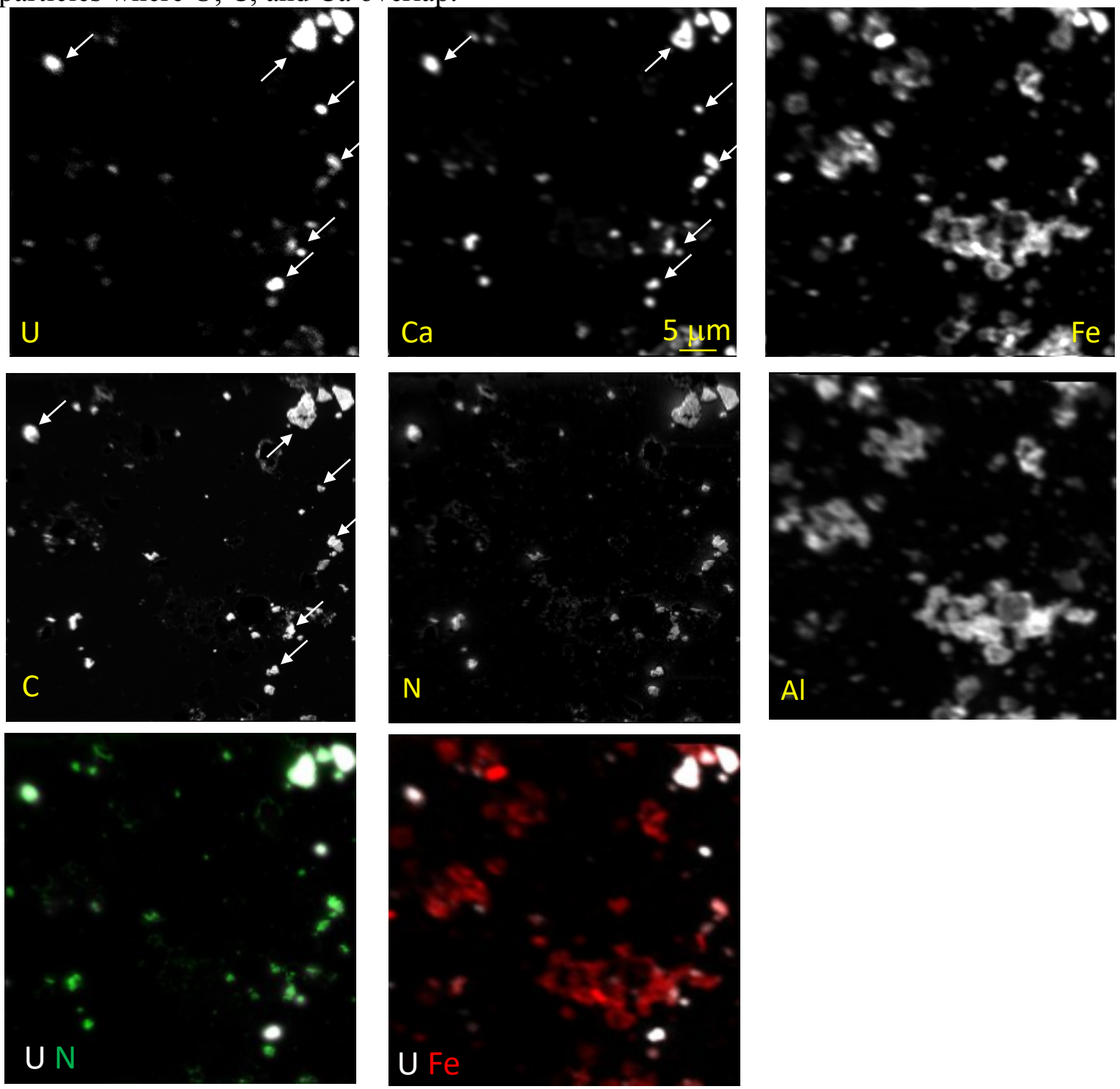
Figure S12: Box plots showing elemental distributions within ROIs for riverbank, light fraction. Box plots showing the median (orange line), upper and lower quartiles (green box), range (green line), and outlying points (green crosses) for the intensities of $\mathrm{U}$, $\mathrm{C}, \mathrm{N}, \mathrm{Ca}, \mathrm{Al}$ and $\mathrm{Fe}$ within all U-containing particles present in the region shown in Figure S11. Each particle is referenced by its ROI number (x-axis). The arrows draw attention to the particles that exhibit the highest $U$ intensities, as well as the other elements that exhibit elevated intensities for those same particles.
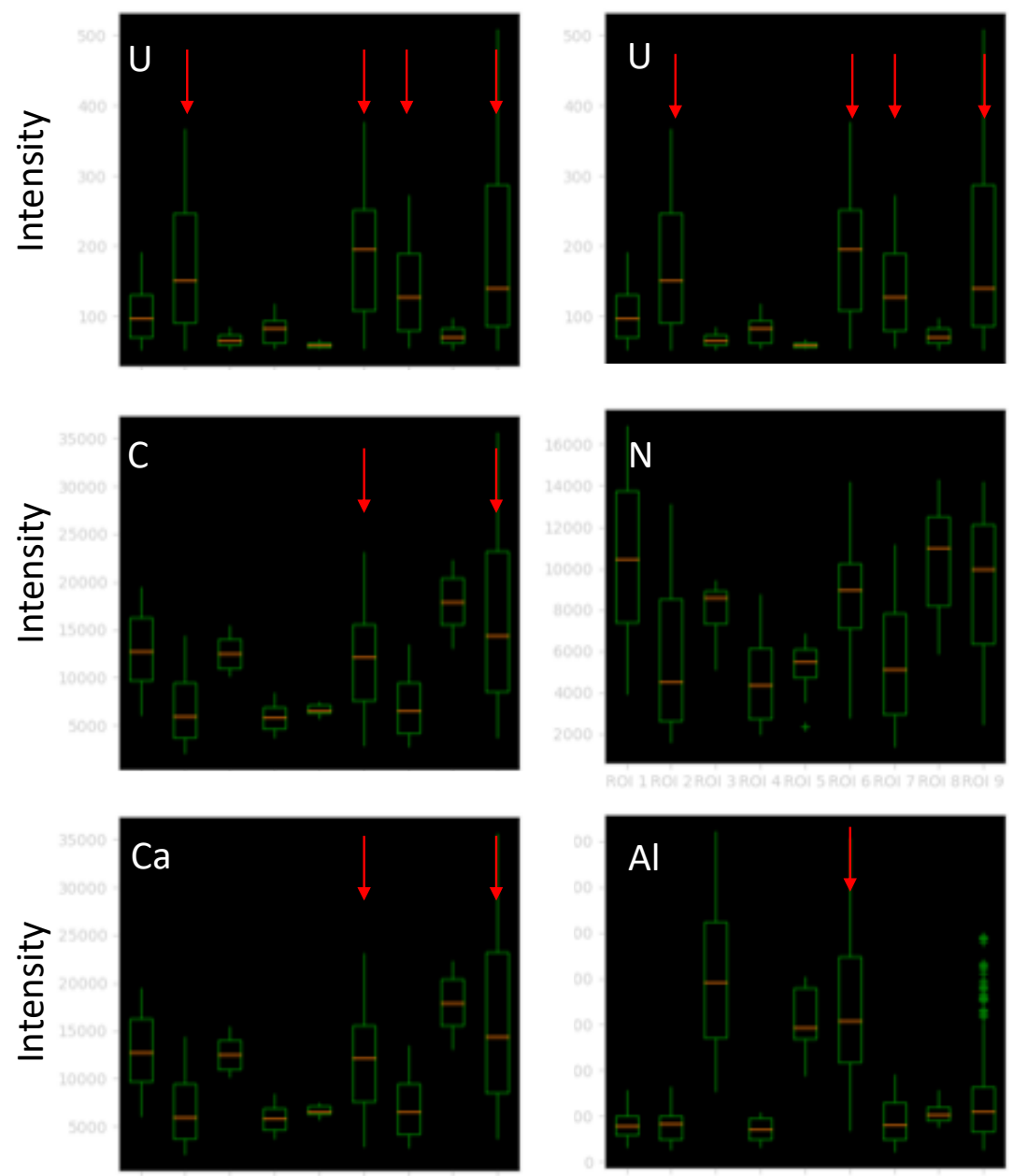

ROI \#

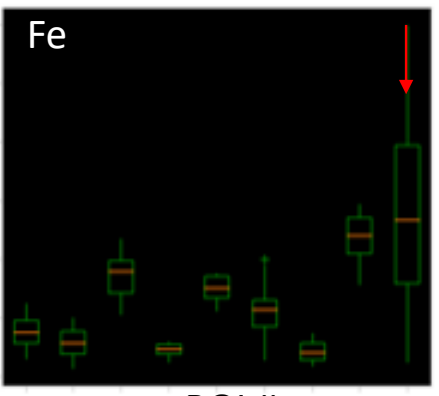

ROI \# 
Figure S13: NanoSIMS images of the riverbank sediment, middle fraction. Arrows indicates particles where $\mathrm{U}$ and $\mathrm{C}$ or $\mathrm{U}$ and $\mathrm{Ca}$ overlap.
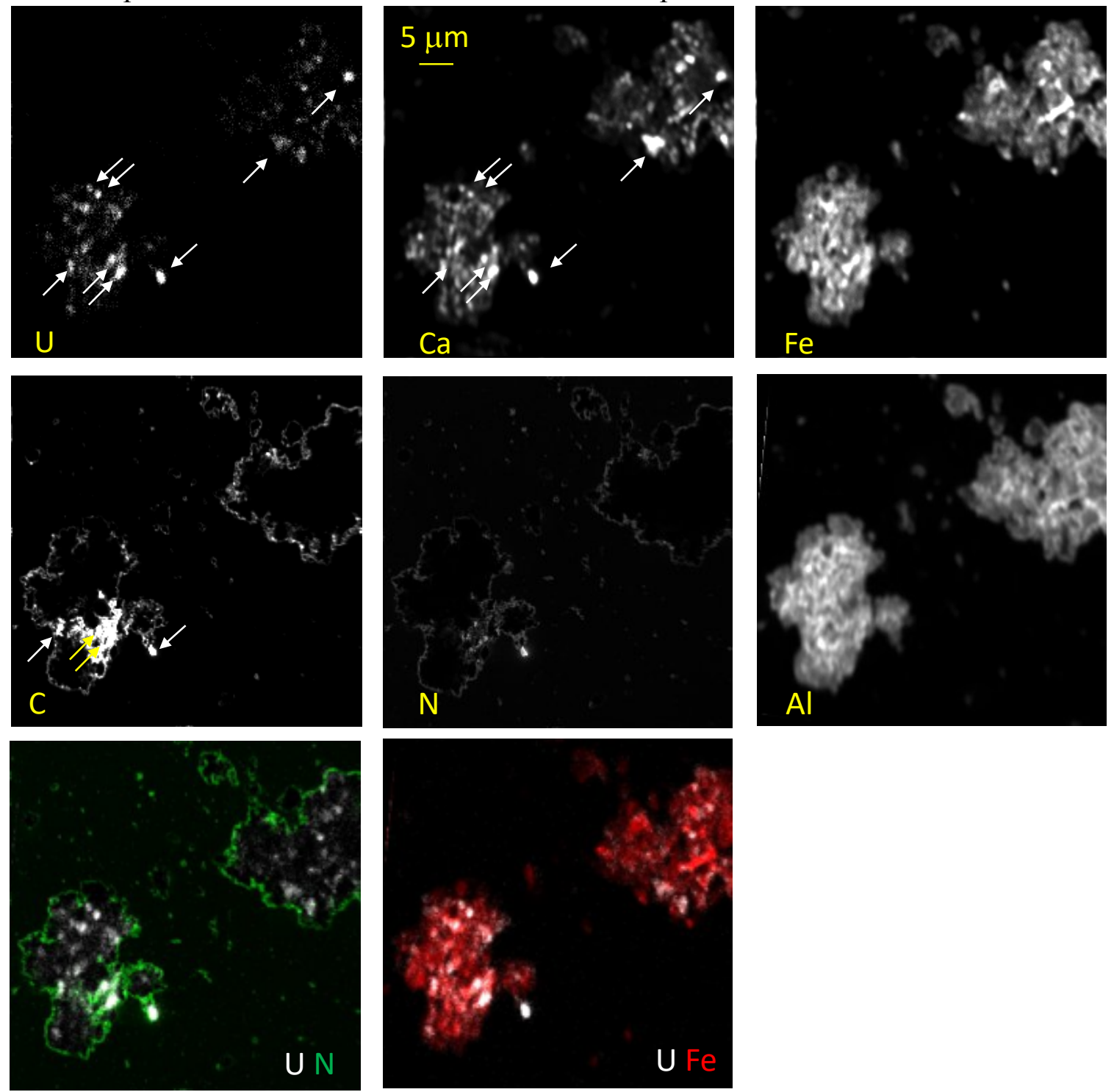
Figure S14: Box plots showing elemental distributions within ROIs for riverbank, middle fraction. Box plots showing the median (orange line), upper and lower quartiles (green box), range (green line), and outlying points (green crosses) for the intensities of $\mathrm{U}$, $\mathrm{C}, \mathrm{N}, \mathrm{Ca}, \mathrm{Al}$ and $\mathrm{Fe}$ within all $\mathrm{U}$-containing particles present in the region shown in Figure S13. Each particle is referenced by its ROI number (x-axis). The arrows draw attention to the particles that exhibit the highest $U$ intensities, as well as the other elements that exhibit elevated intensities for those same particles.
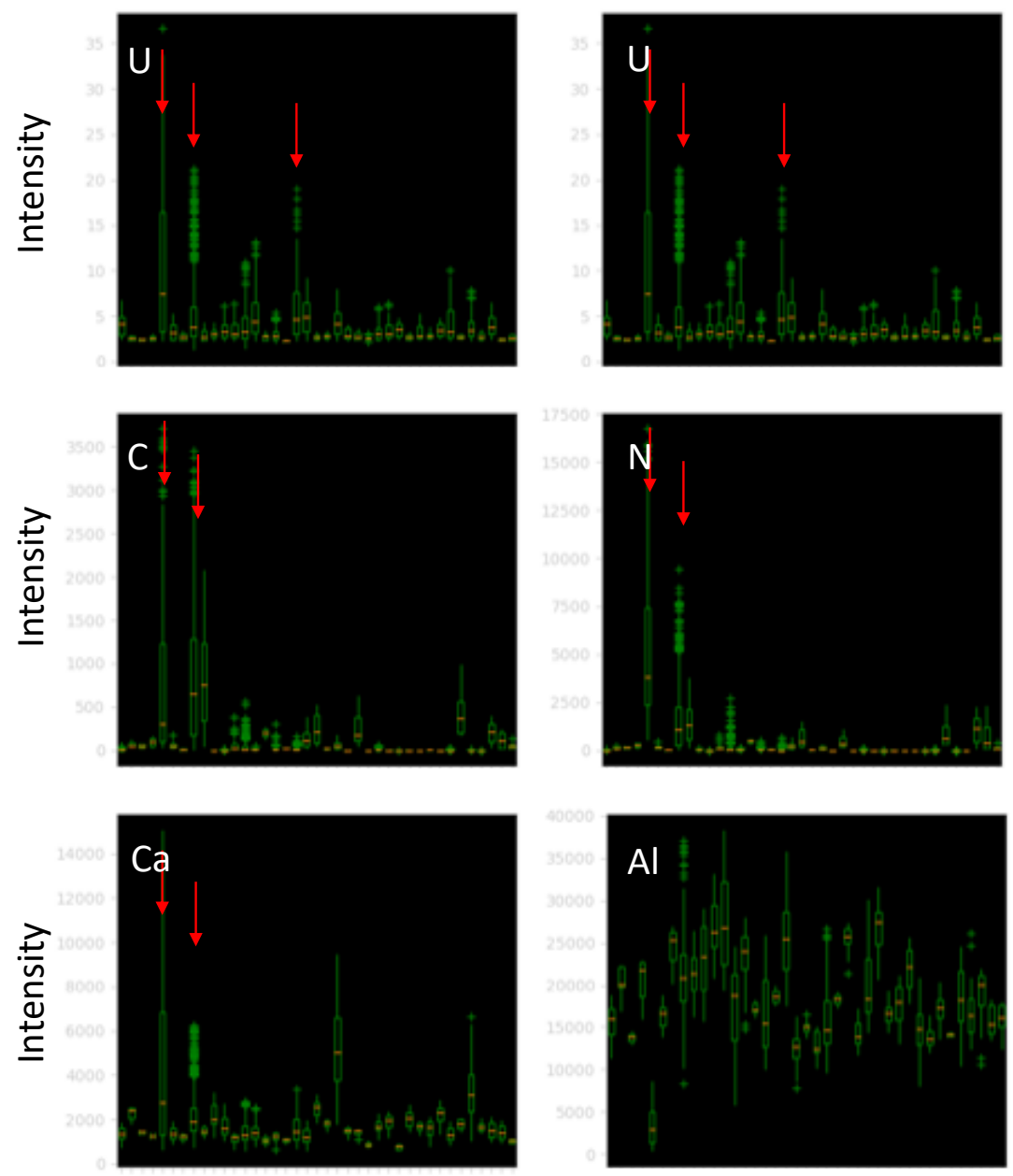

ROI \#

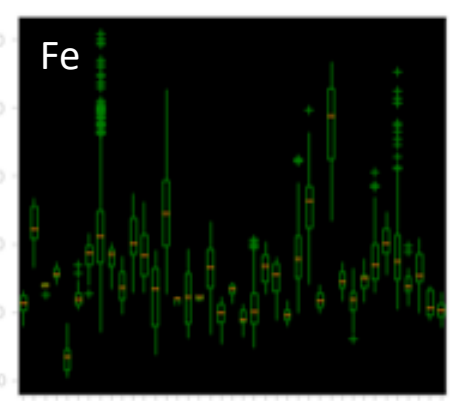

ROI \# 
Figure S15: NanoSIMS images of the riverbank sediment, middle fraction. Arrows indicate particles where $\mathrm{U}, \mathrm{C}$ and $\mathrm{Ca}$ overlap.
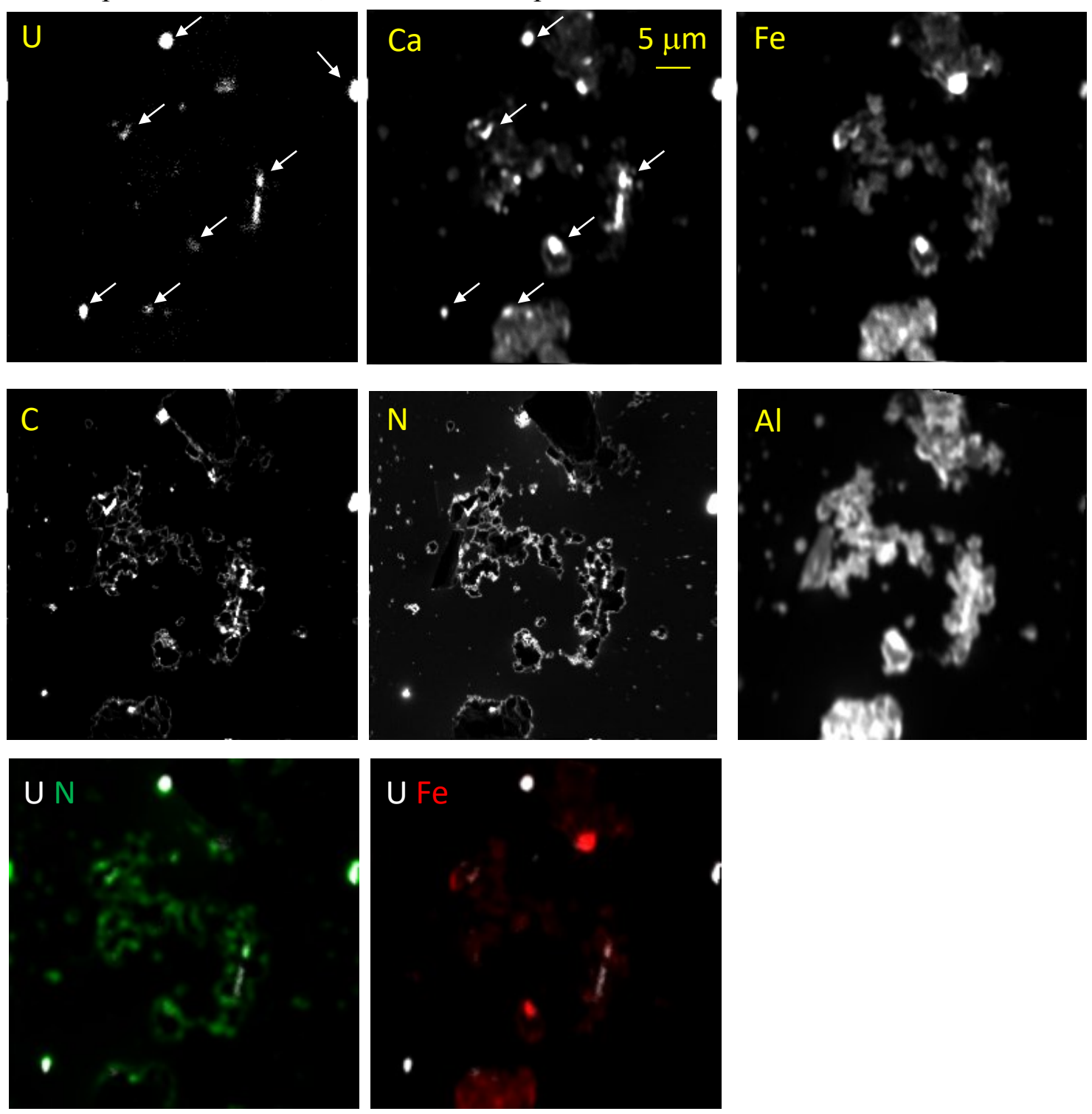
Figure S16: Box plots showing elemental distributions within ROIs for riverbank, middle fraction. Box plots showing the median (orange line), upper and lower quartiles (green box), range (green line), and outlying points (green crosses) for the intensities of $\mathrm{U}$, $\mathrm{C}, \mathrm{N}, \mathrm{Ca}, \mathrm{Al}$ and $\mathrm{Fe}$ within all U-containing particles present in the region shown in Figure S15. Each particle is referenced by its ROI number (x-axis). The arrows draw attention to the particles that exhibit the highest $U$ intensities, as well as the other elements that exhibit elevated intensities for those same particles.
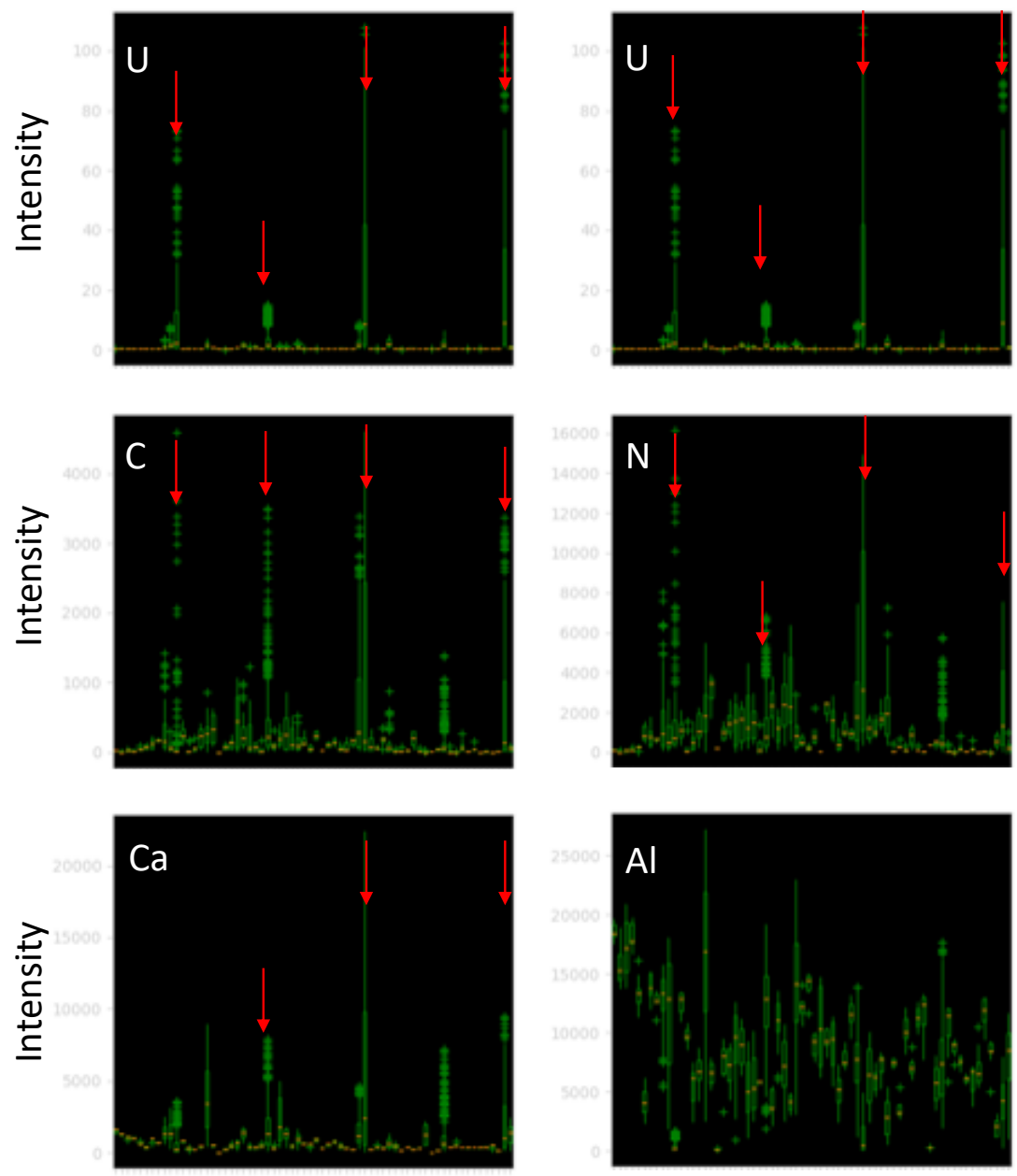

ROI \#

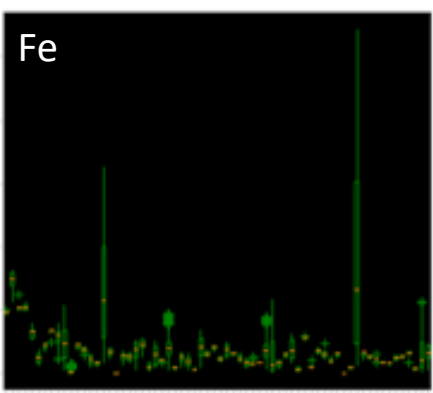

ROI \# 


\section{Organic Matter Distribution and Speciation from STXM}

The $\mathrm{C}$ speciation in the density fractionated sediment samples was first investigated using principal component analysis (PCA) and cluster analysis (CA). In CA, the pixels in the stack map are clustered according to whether they have similar weightings of the principal components identified using $\mathrm{PCA}^{4}$. Cluster analysis can thus be used to identify chemically distinct areas within the sample and to assess the spatial variability in $\mathrm{C}$ speciation without prior knowledge of the $\mathrm{C}$ species that comprise the sample. Furthermore, by averaging the pixels within each cluster to generate a spectrum, it is possible to identify the dominant peak resonances, and thus dominant functional group classes, found within that region of the sample.

Stack maps were analyzed between 280 and $295 \mathrm{eV}$ because this region contains information on $1 \mathrm{~s} \rightarrow \pi^{*}$ transitions that are sensitive to functional group type. However, in many cases it was necessary to limit the range to between 284 and $295 \mathrm{eV}$ because there was an artifact in the samples (a dip in the intensity between 280 and $284 \mathrm{eV}$ ) that arose due to contamination of the beamline optics with carbon. The number of principal components was selected based on the inflection point in a plot of component weight versus component number (the "knee" of the plot, as referred to by Lerotic et al. ${ }^{4}$ ). We selected the number of clusters to be $c a$. twice the number of principle components, finding that having more rather than fewer clusters enhanced our ability to observe chemical differences within the samples. The samples were drop-deposited, which led all samples to be variable in terms of their thickness. Such thickness differences were manifest in terms of altered peak intensities in the cluster spectra (maximum peak intensities were disproportionately attenuated in thick samples). The gamma value was set equal to 0.3 to improve sensitivity to spectra comprising a small number of pixels ${ }^{4}$. Figures S17 - S18 show the results of the PCA-CA for the three density fractions for both sediments, including cluster regions and corresponding cluster spectra.

Fingerprinting analysis was used in combination with morphology to identify the types of organics present within the samples. Peak resonances and the functional groups to which they correspond have been summarized based on literature-reported values in Table S7. The functional group composition of sample cluster spectra was qualitatively assessed based on comparison of their peak energies to these published values (Tables S8-S13). Sample cluster spectra were further categorized based on which functional groups are expected to dominate the spectra of plant and microbial materials. Microbial cells are rich in proteins and spectra collected from bacteria are typically identical to spectra collected from reference proteins ${ }^{5}$. Thus, sample areas with spectra that were characteristic of proteins were assigned to be microbial in origin (in fact, these areas sometimes had celllike morphologies). Lignin, a common plant polymer, is characterized by large peaks at $c a$. 285, $267-287$ and $288 \mathrm{eV}^{3}$. Spectra with similar features were apparent in some sample areas and we concluded these areas comprised lignin or partially-degraded lignin. We also characterized so-called "partially degraded organic matter", which did not resemble a particular biological macromolecule, but which appear similar to spectra commonly observed in soils and microbially-processed material associated with minerals ${ }^{5-7}$. 
Table S7: Peak energies associated with organic C functional groups.

\begin{tabular}{|c|c|}
\hline $\begin{array}{c}\text { Peak energy } \\
(\mathbf{e V})^{\mathbf{1}}\end{array}$ & Functional group \\
\hline $285.0-285.5$ & Aromatic C \\
\hline $285.8-286.4$ & $\begin{array}{c}\text { Carbonyl substituted } \\
\text { aromatic (ketone) }\end{array}$ \\
\hline $287.1-287.4$ & Aliphatic C, phenolic C \\
\hline $288.2-288.3$ & Amide C \\
\hline $288.2-288.7$ & Carboxylate groups \\
\hline $289.1-289.6$ & $\begin{array}{c}\text { O-alkyl C (alcohols and } \\
\text { ethers) }\end{array}$ \\
\hline $290.3-290.6$ & Carbonate \\
\hline
\end{tabular}

${ }^{1}$ The energy ranges for each functional group and the corresponding electronic transition were compiled from Solomon et al. ${ }^{8}$, Lawrence et al. ${ }^{9}$, Haberstroh et al. ${ }^{10}$, Cody et al. ${ }^{11}$ and Wan et al. ${ }^{12}$. 
Figure S17: PCA-CA of oxbow lake sediment density fractions. Map of carbon distribution $($ green $=288.2 \mathrm{eV}$, red $=289.1 \mathrm{eV})$ and mineral distribution $($ blue $=280.0 \mathrm{eV}$ ) is shown in the images in the first (left-most) column. The regions where stack maps were collected are indicated by gold boxes. Cluster maps are shown in the second column and corresponding C K-edge XAS are shown in the last column. Clusters are color coded and spectra for the corresponding cluster are shown in the same color. Note that the first cluster is always the background (i.e. where particles are absent) so no spectrum for cluster 1 is provided.

Oxbow Lake, light fraction
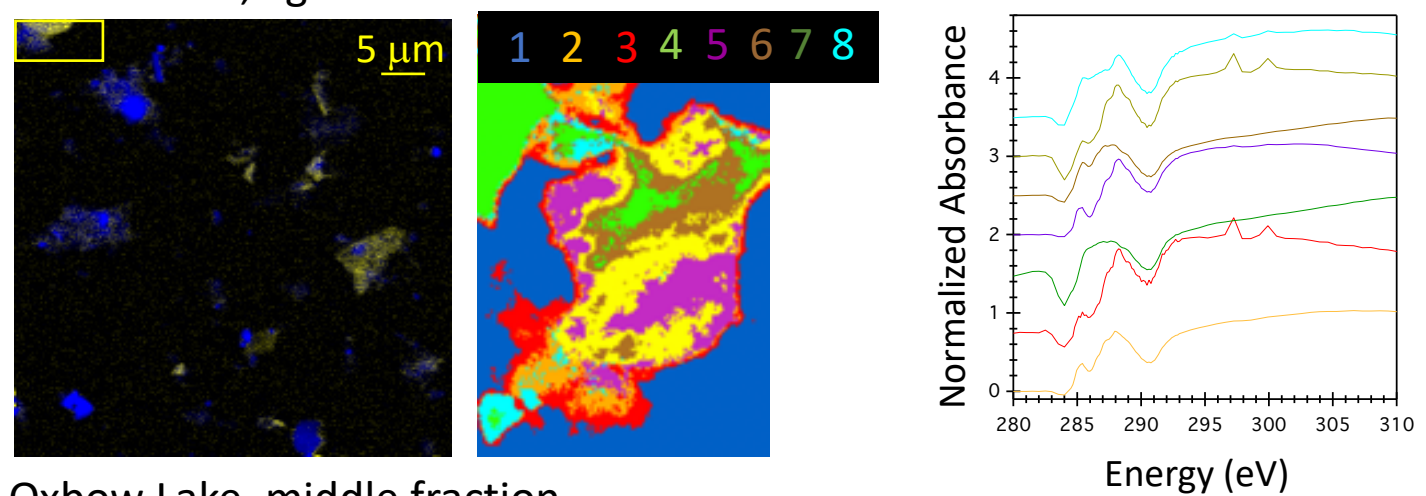

Oxbow Lake, middle fraction
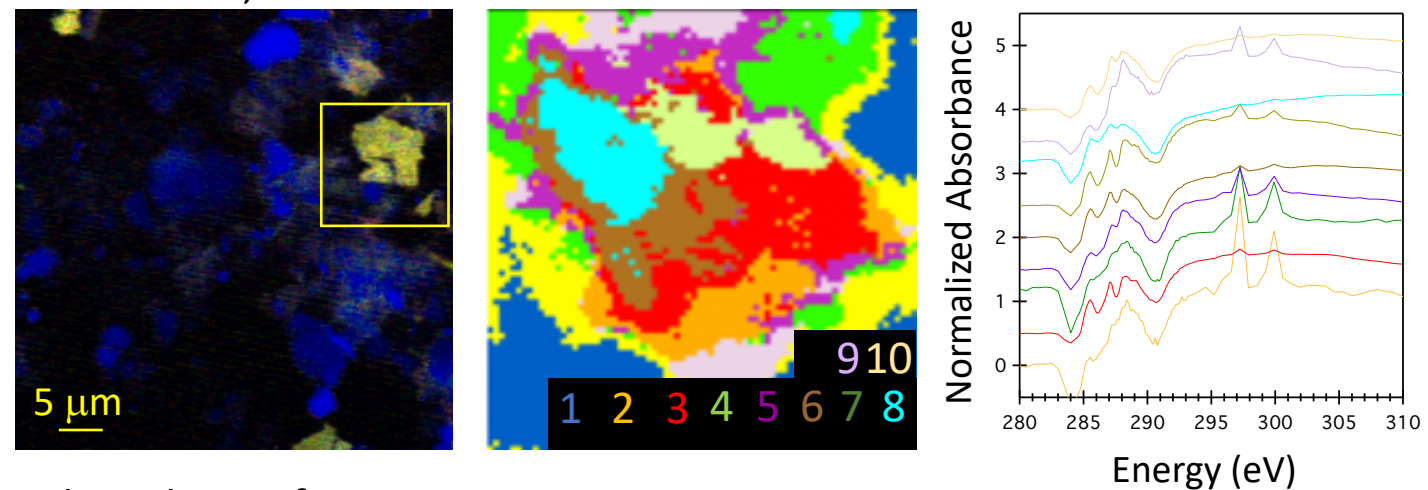

Oxbow, heavy fraction
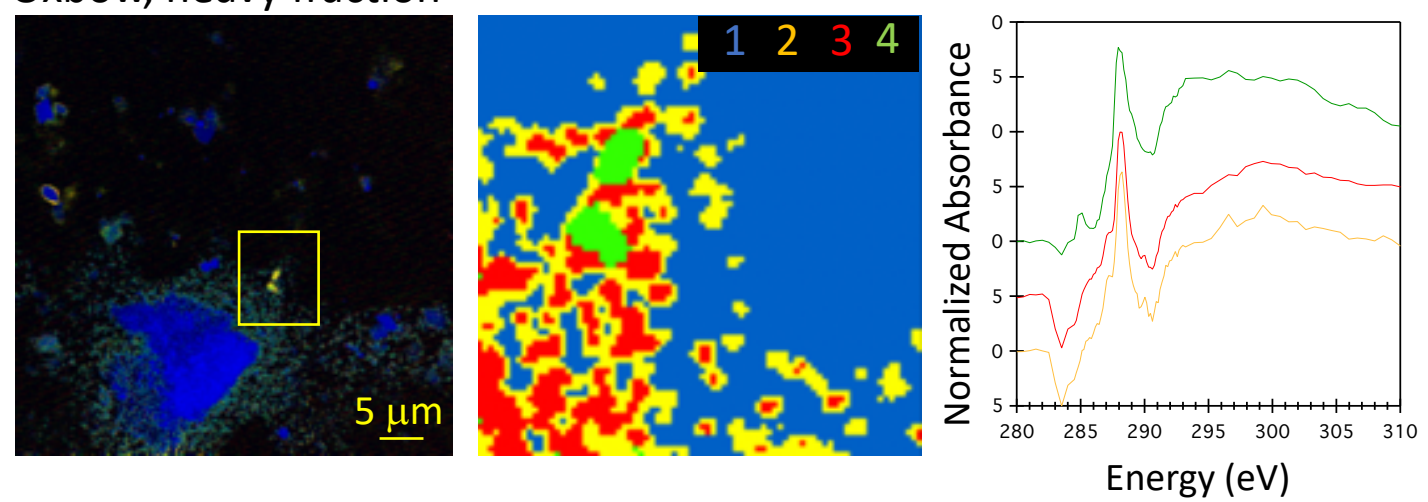
Table S8: Peak energies for cluster spectra shown for oxbow lake, light.

\begin{tabular}{|c|c|c|c|c|c|c|c|}
\hline Sample & Cluster & Aromatic & Phenol & Carboxyl & Alcohol & Carbonate & Comments \\
\hline $\begin{array}{c}\text { Oxbow } \\
\text { Lake, } \rho< \\
\text { 1.6 Region } \\
3\end{array}$ & 2 & 285.4 & 287.2 & 288 & & & $\begin{array}{c}\text { partially- } \\
\text { degraded organic } \\
\text { matter }\end{array}$ \\
\hline & 3 & 285.4 & 287.5 & 288.2 & & & $\begin{array}{c}\text { partially- } \\
\text { degraded organic } \\
\text { matter }\end{array}$ \\
\hline & 4 & & & & & & $\begin{array}{l}\text { spectra too } \\
\text { distorted for } \\
\text { interpretation }\end{array}$ \\
\hline & 5 & 285.4 & 287.2 & 288.2 & & & $\begin{array}{c}\text { partially- } \\
\text { degraded organic } \\
\text { matter }\end{array}$ \\
\hline & 6 & 285.4 & $\begin{array}{l}287.2 \\
287.8 \\
\end{array}$ & 288.8 & & & $\begin{array}{c}\text { partially- } \\
\text { degraded organic } \\
\text { matter }\end{array}$ \\
\hline & 7 & 285.4 & 287.2 & 288.2 & & & $\begin{array}{c}\text { partially- } \\
\text { degraded organic } \\
\text { matter }\end{array}$ \\
\hline & 8 & 285.4 & 287 & 288.2 & & & $\begin{array}{c}\text { partially- } \\
\text { degraded organic } \\
\text { matter }\end{array}$ \\
\hline
\end{tabular}


Table S9: Peak energies for cluster spectra for oxbow lake, middle.

\begin{tabular}{|c|c|c|c|c|c|c|c|}
\hline Sample & Cluster & Aromatic & Ketone & Phenol & Carboxyl & Alcohol & Comments \\
\hline \multirow[t]{9}{*}{$\begin{array}{c}\text { Oxbow } \\
\text { Lake, } \\
1.6<\rho<2.4 \\
\text { Region } 1 \\
\end{array}$} & 2 & 285.4 & & 287.2 & 288.3 & & $\begin{array}{c}\text { partially- } \\
\text { degraded } \\
\text { organic matter }\end{array}$ \\
\hline & 3 & 285.4 & & 287.2 & 288.3 & 289.2 & lignin \\
\hline & 4 & & & & & & $\begin{array}{c}\text { spectra too } \\
\text { distorted for } \\
\text { interpretation }\end{array}$ \\
\hline & 5 & 285.4 & & 287.2 & 288.2 & & lignin \\
\hline & 6 & 285.4 & & 287.2 & 288.2 & & lignin \\
\hline & 7 & 285.4 & & 287.2 & 288.2 & 289.2 & lignin \\
\hline & 8 & 285.4 & & 287.2 & 288.2 & & $\begin{array}{c}\text { partially- } \\
\text { degraded } \\
\text { organic matter }\end{array}$ \\
\hline & 9 & 285.4 & 286.4 & 287 & 288 & & $\begin{array}{c}\text { partially- } \\
\text { degraded } \\
\text { organic matter }\end{array}$ \\
\hline & 10 & 285.4 & & 287.2 & 288 & & $\begin{array}{c}\text { partially- } \\
\text { degraded } \\
\text { organic matter }\end{array}$ \\
\hline
\end{tabular}

Table S10: Peak energies for cluster spectra for oxbow lake, heavy.

\begin{tabular}{|c|c|c|c|c|c|c|}
\hline Sample & Cluster & Aromatic & Phenol & Carboxyl & Alcohol & Comments \\
\hline $\begin{array}{c}\text { Oxbow, } \\
\rho>2.4 \\
\text { Region } 1\end{array}$ & 2 & & 287.3 & 288.3 & & $\begin{array}{c}\text { microbial/partially- } \\
\text { degraded organic } \\
\text { matter }\end{array}$ \\
\hline & 3 & & 287.3 & 288.3 & & $\begin{array}{c}\text { microbial/partially- } \\
\text { degraded organic } \\
\text { matter }\end{array}$ \\
\hline & 4 & 285.1 & & 288.2 & & microbial \\
\hline
\end{tabular}


Figure S18: PCA-CA of riverbank sediment density fractions. Map of carbon distribution $($ green $=288.2 \mathrm{eV}$, red $=289.1 \mathrm{eV})$ and mineral distribution $($ blue $=280.0 \mathrm{eV}$ ) is shown in the images in the first (left-most) column. The regions where stack maps were collected are indicated by gold boxes. Cluster maps are shown in the second column and corresponding C K-edge XAS are shown in the last column. Clusters are color coded and spectra for the corresponding cluster are shown in the same color. Note that the first cluster is always the background (i.e. where particles are absent) so no spectrum for cluster 1 is provided.
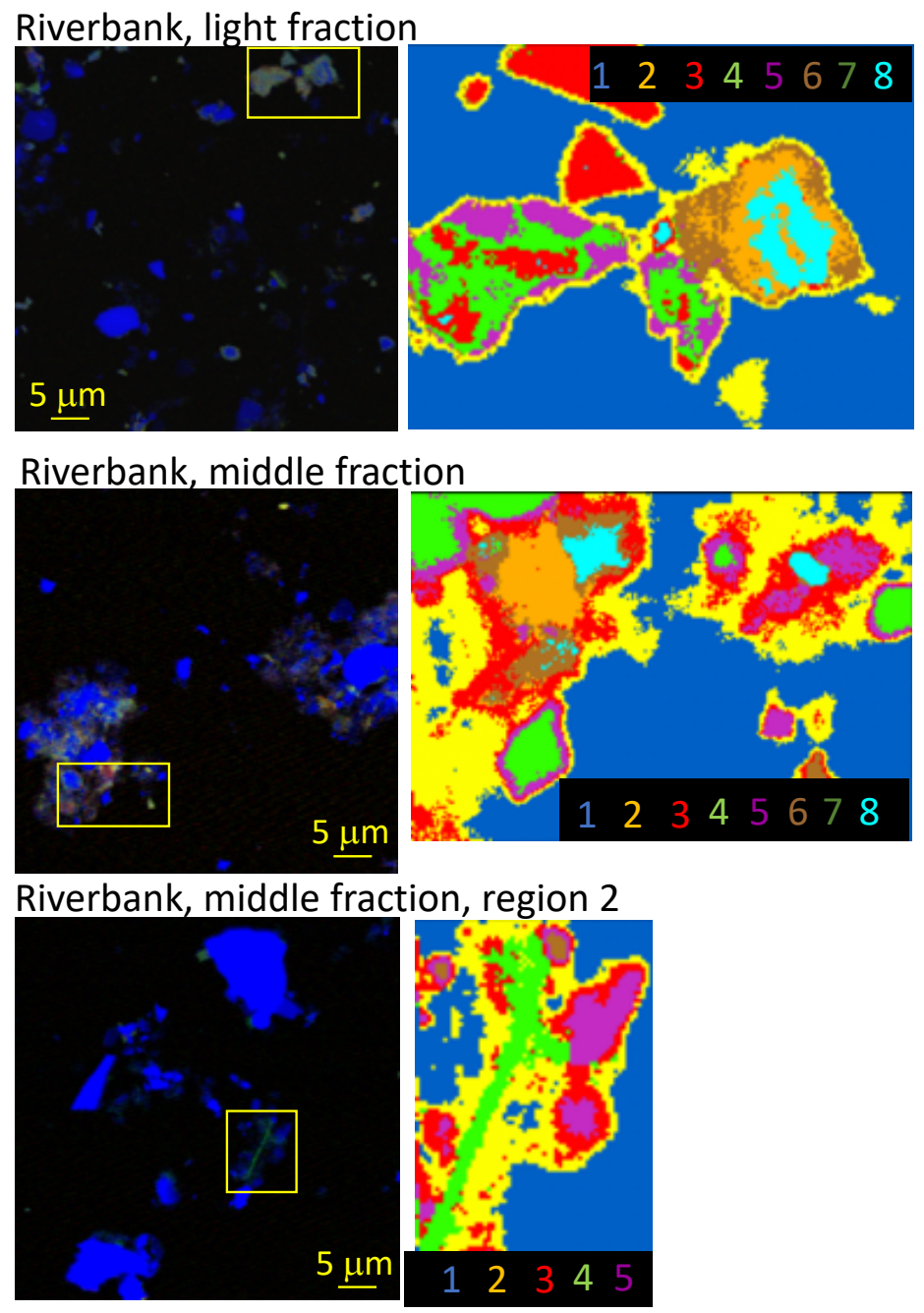

Riverbank, heavy fraction
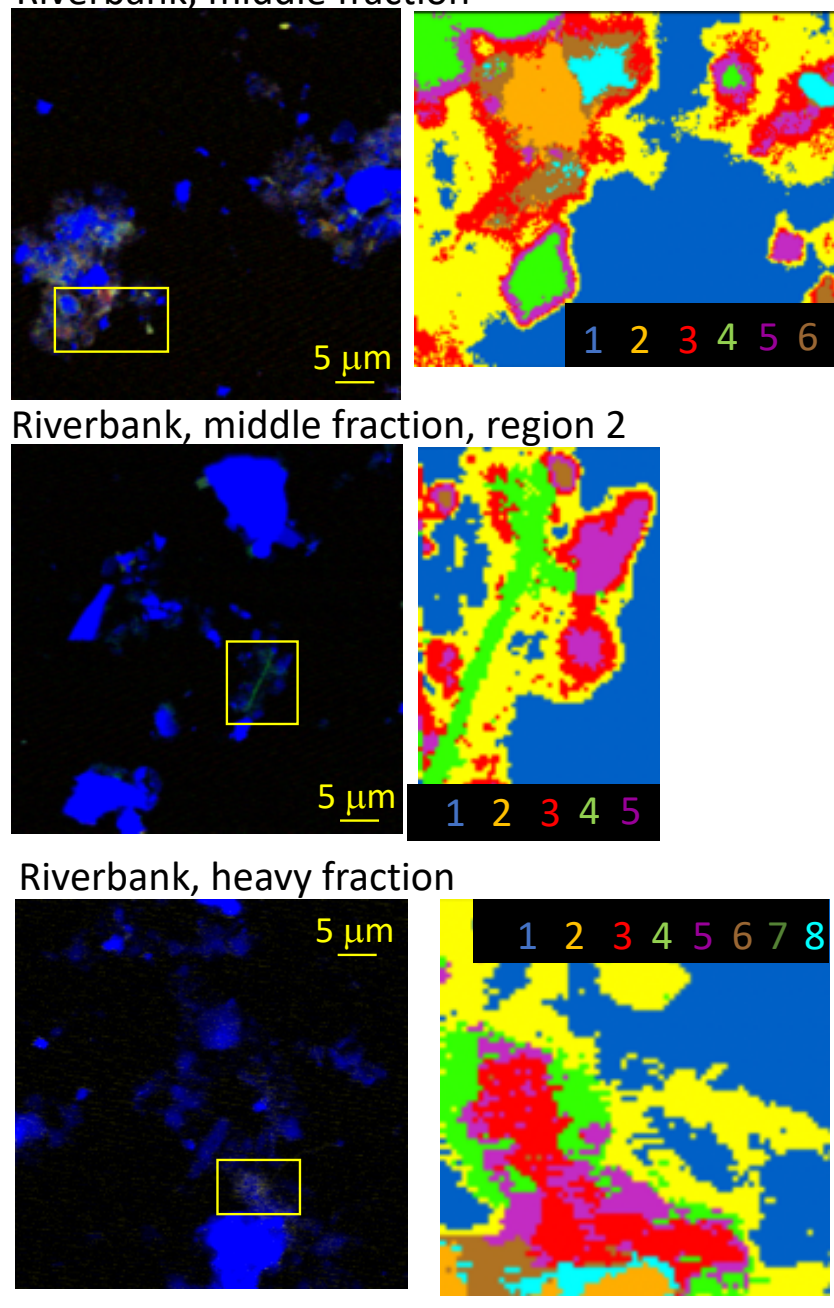

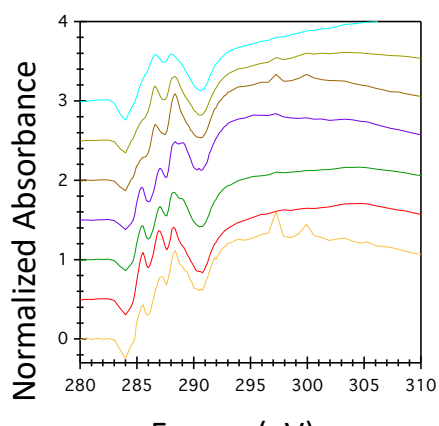

Energy (eV)
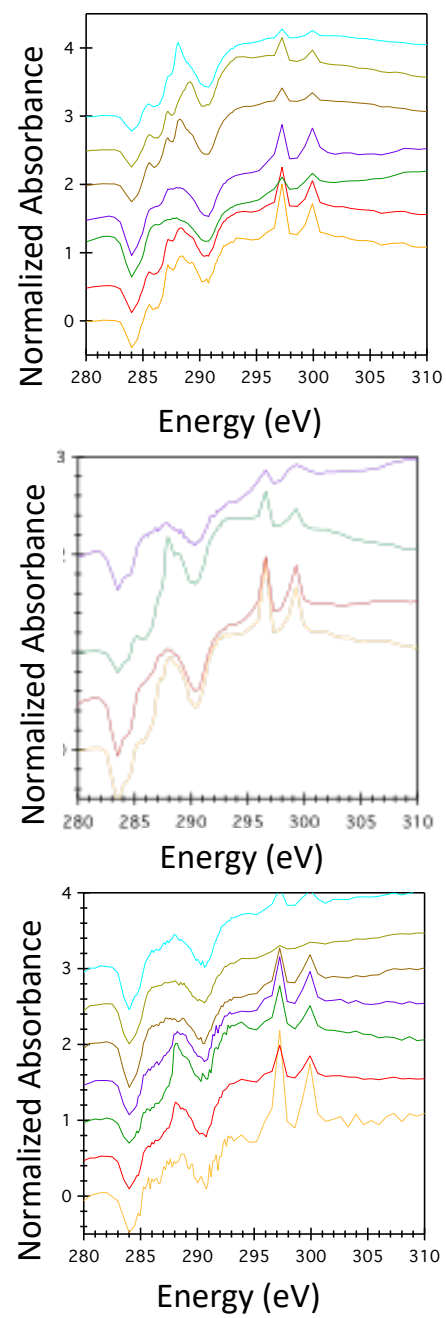
Table S11: Peak energies for cluster spectra shown for riverbank, light.

\begin{tabular}{|c|c|c|c|c|c|c|c|}
\hline Sample & Cluster & Aromatic & Ketone & Phenol & Carboxyl & Alcohol & Comments \\
\hline $\begin{array}{c}\text { Riverbank, } \\
\rho<1.6 \\
\text { Region 1 }\end{array}$ & 2 & 285.5 & & & & & lignin \\
\hline & 3 & 285.5 & & 287 & 288.2 & & lignin \\
\hline & 4 & 285.5 & & 287 & 288.2 & 289 & lignin \\
\hline & 5 & 285.5 & & 287 & 288.2 & 289.1 & lignin \\
\hline & 6 & 285.5 & 286.6 & & 288.2 & & lignin derivative \\
\hline & 7 & 285.5 & 286.6 & & 288.2 & & lignin derivative \\
\hline & 8 & & & & & & $\begin{array}{c}\text { spectra too } \\
\text { distorted for } \\
\text { interpretation }\end{array}$ \\
\hline
\end{tabular}

Table S12: Peak energies for cluster spectra shown for riverbank, middle.

\begin{tabular}{|c|c|c|c|c|c|c|}
\hline Sample & Cluster & Aromatic & Phenol & Carboxyl & Alcohol & Comments \\
\hline $\begin{array}{c}\text { Riverbank, } \\
\text { Region 1 }\end{array}$ & 2 & 285.5 & 287.2 & 288.3 & 289.3 & $\begin{array}{c}\text { partially-degraded organic } \\
\text { matter }\end{array}$ \\
\hline & 3 & 285.5 & 287.2 & 288.3 & 289.5 & $\begin{array}{c}\text { partially-degraded organic } \\
\text { matter }\end{array}$ \\
\hline & 4 & & & & & $\begin{array}{c}\text { spectra too distorted for } \\
\text { interpretation }\end{array}$ \\
\hline & 6 & 285.5 & 287.2 & 288.3 & 289.3 & $\begin{array}{c}\text { spectra too distorted for } \\
\text { interpretation }\end{array}$ \\
\hline & 7 & 285.5 & 287.2 & & 289.1 & lignin derivative \\
\hline & 8 & 285.5 & 287.2 & 288 & & partially-degraded organic \\
& & & & & & \\
\hline
\end{tabular}


Table S13: Peak energies for cluster spectra shown for riverbank, middle.

\begin{tabular}{|c|c|c|c|c|c|c|}
\hline Sample & Cluster & Aromatic & Phenol & Carboxyl & Alcohol & Comments \\
\hline $\begin{array}{c}\text { Riverbank, } \\
1.6<\rho<2.4 \\
\text { Region } 1\end{array}$ & 2 & 285.5 & 287.4 & 288.3 & & partially-degraded organic matter \\
\hline & 3 & & & & & $\begin{array}{c}\text { spectra too distorted for } \\
\text { interpretation }\end{array}$ \\
\hline & 4 & 285.4 & 287.2 & 288.1 & 289.1 & microbial \\
\hline & 5 & & & & & $\begin{array}{l}\text { spectra too distorted for } \\
\text { interpretation }\end{array}$ \\
\hline
\end{tabular}

Table S14: Peak energies for cluster spectra shown for riverbank, heavy.

\begin{tabular}{|c|c|c|c|c|c|c|}
\hline Sample & Cluster & Aromatic & Phenol & Carboxyl & Alcohol & Comments \\
\hline \multirow[t]{7}{*}{$\begin{array}{c}\text { Riverbank, } \\
\rho>2.4 \\
\text { Region } 1 \\
\end{array}$} & 2 & & & & & $\begin{array}{c}\text { spectra too distorted for } \\
\text { interpretation }\end{array}$ \\
\hline & 3 & & & 288 & 289 & partially-degraded organic matter \\
\hline & 4 & & & 288.2 & 289 & partially-degraded organic matter \\
\hline & 5 & & & & & $\begin{array}{l}\text { spectra too distorted for } \\
\text { interpretation }\end{array}$ \\
\hline & 6 & & & & & $\begin{array}{c}\text { spectra too distorted for } \\
\text { interpretation }\end{array}$ \\
\hline & 7 & & & & & $\begin{array}{c}\text { spectra too distorted for } \\
\text { interpretation }\end{array}$ \\
\hline & 8 & & & & & $\begin{array}{l}\text { spectra too distorted for } \\
\text { interpretation }\end{array}$ \\
\hline
\end{tabular}

\section{References:}

1. Koziol, B.; Okuinghttons, R.; Theurich, G.; Vasquez, S. ESMPy: Python interface to the Earth System Modeling Framework, University of Colorado, Boulder: 2018.

2. Webb, S. M. SMAK: Sam's MicroAnalysis Toolkit, Stanford Synchrotron Radiation Lightsource, Stanford, CA, 2018. 
3. Bone, S. E.; Dynes, J. J.; Cliff, J.; Bargar, J. R., Uranium(IV) adsorption by natural organic matter in anoxic sediments. Proc. Natl. Acad. Sci. U.S.A. 2017, 114 (4), 711716.

4. $\quad$ Lerotic, M.; Jacobsen, C.; Schafer, T.; Vogt, S., Cluster analysis of soft X-ray spectromicroscopy data. Ultramicroscopy 2004, 100, 35-57.

5. $\quad$ Keiluweit, M.; Bougoure, J. J.; Zeglin, L. H.; Myrold, D. D.; Weber, P. K.; PettRidge, J.; Kleber, M.; Nico, P. S., Nano-scale investigation of the association of microbial nitrogen residues with iron (hydr)oxides in a forest soil O-horizon. Geochim. Cosmochim. Acta 2012, 95 (0), 213-226.

6. Solomon, D.; Lehmann, J.; Harden, J.; Wang, J.; Kinyangi, J.; Heymann, K.; Karunakaran, C.; Lu, Y.; Wirick, S.; Jacobsen, C., Micro- and nano-environments of carbon sequestration: Multi-element STXM-NEXAFS spectromicroscopy assessment of microbial carbon and mineral associations. Chem. Geol. 2012, 329 (0), 53-73.

7. Cismasu, A. C.; Williams, K. H.; Nico, P. S., Iron and Carbon Dynamics during Aging and Reductive Transformation of Biogenic Ferrihydrite. Environ. Sci. Technol. 2016, 50 (1), 25-35.

8. $\quad$ Solomon, D.; Lehmann, J.; Kinyangi, J.; Liang, B. Q.; Heymann, K.; Dathe, L.; Hanley, K.; Wirick, S.; Jacobsen, C., Carbon (1s) NEXAFS Spectroscopy of Biogeochemically Relevant Reference Organic Compounds. Soil Sci Soc Am J 2009, 73 (6), 1817-1830.

9. Lawrence, J. R.; Swerhone, G. D. W.; Leppard, G. G.; Araki, T.; Zhang, X.; West, M. M.; Hitchcock, A. P., Scanning transmission X-ray, laser scanning, and transmission electron microscopy mapping of the exopolymeric matrix of microbial biofilms. Appl. Environ. Microbiol. 2003, 69 (9), 5543-5554.

10. Haberstroh, P. R.; Brandes, J. A.; Gelinas, Y.; Dickens, A. F.; Wirick, S.; Cody, G., Chemical composition of the graphitic black carbon fraction in riverine and marine sediments at sub-micron scales using carbon X-ray spectromicroscopy. Geochim. Cosmochim. Acta 2006, 70 (6), 1483-1494.

11. Cody, G. D.; Ade, H.; Wirick, S.; Mitchell, G. D.; Davis, A., Determination of chemical-structural changes in vitrinite accompanying luminescence alteration using C-NEXAFS analysis. Org. Geochem. 1998, 28 (7-8), 441-455.

12. Wan, J.; Tyliszczak, T.; Tokunaga, T. K., Organic carbon distribution, speciation, and elemental correlations within soil microaggregates: Applications of STXM and NEXAFS spectroscopy. Geochim. Cosmochim. Acta 2007, 71 (22), 5439-5449. 